
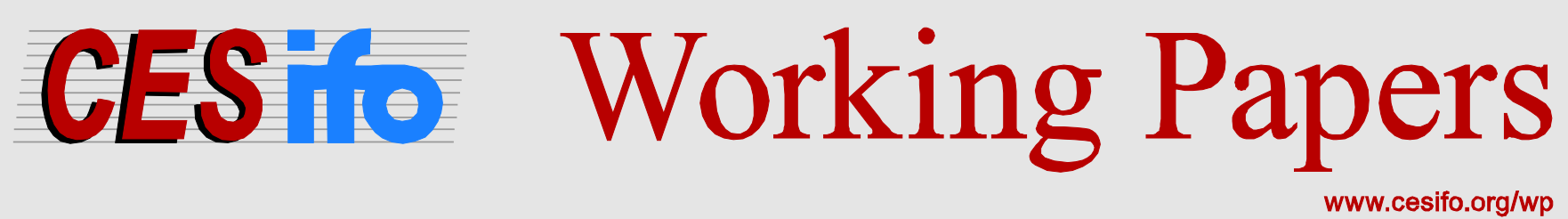

\title{
Bank Capital Regulation with an Opportunistic Rating Agency
}

\author{
Matthias Efing
}

\author{
CESIFO WORKING PAPER NO. 4267 \\ CATEGORY 7: MONETARY POLICY AND INTERNATIONAL FinANCE \\ JUNE 2013
}

Presented at CESifo Area Conference on Macro, Money \& International Finance, February 2013

An electronic version of the paper may be downloaded

- from the SSRN website:

WwW.SSRN.com

- from the RePEc website:

www.RePEc.org

- from the CESifo website:

www.CESifo-group.org/wp

\section{CESifo}




\title{
Bank Capital Regulation with an Opportunistic Rating Agency
}

\begin{abstract}
This paper models the strategic interaction between a rating agency, a bank and a bank regulator who lacks information about bank asset risk. The regulator can either (1) make bank capital requirements contingent on credit ratings; or (2) set rating-independent capital requirements. Truthful ratings provide efficiency gains because they allow the regulator to constrain high risk bank investment without simultaneously reducing overall investment volume. However, if collusion between the rating agency and the bank corrupts rating quality, rating-independent regulation enhances welfare. The welfare benefits are largest if regulators maintain rating-contingent capital requirements and discipline rating agencies.
\end{abstract}

JEL-Code: D820, G210, G240, G280.

Keywords: bank regulation, Lucas critique, collusion, ratings inflation, risk-shifting.

Matthias Efing
Swiss Finance Institute \& University of Geneva
Bâtiment Pignon
40 Bd du Pont d'Arve
Switzerland - 1211 Genève
matthias.efing@unige.ch

May 16, 2013

First draft: May, 2012

I am particularly grateful to Harald Hau, Martin Hellwig and Norman Schürhoff. I also appreciate helpful comments of Peter DeMarzo, Rajna Gibson Brandon, Stefan Hirth, Semyon Malamoud, David Marqués Ibañez, Marcus M. Opp, Rémy Praz, Jean-Charles Rochet and René M. Stulz. The paper benefited from participants at the "CESifo Area Conference on Macro, Money and International Finance 2013", at the annual meeting of the German Finance Association in 2012, at the "Annual Swiss Doctoral Workshop in Finance 2012" in Gerzensee and at the "Spring Meeting of Young Economists 2012" at the Centre for European Economic Research. I also thank seminar participants at the Max Planck Institute for Research on Collective Goods, at the universities of Geneva, Lausanne and Zürich and at the École Polytechnique Fédérale de Lausanne. 


\section{Introduction}

Asymmetric information between the financial industry and its regulators impedes the calibration of minimum bank capital requirements to asset risk. Therefore, regulators have increasingly relied on credit ratings as a source of information. Unfortunately, this outsourcing of risk assessment to private agencies can turn into a Trojan horse if rating agencies inflate credit ratings. The Dodd-Frank Act consequently mandates the complete elimination of rating-contingent capital requirements (henceforth RCCR). Adherents of RCCR on the other hand argue that higher rating-independent capital requirements (RICR) would constrain credit supply to the real economy. This paper adopts a normative point of view on this question and researches the optimal design of bank regulation. Importantly, the choice between RCCR and RICR influences the incentives of agents in the financial system in the sense of the Lucas critique. The introduction of RCCR itself can incentivize formerly honest raters to deliberately inflate ratings if this relaxes regulatory constraints on bank investment.

My research on RCCR is motivated by three observations. (1) Credit ratings of structured debt were apparently of inflated quality. They required massive downgrades in 2007 and 2008 (Benmelech \& Dlugosz, 2009) and even $A A A$-rated MBS performed so badly that their ABX dropped by around 70\% between January 2007 and December 2008 according to Brunnermeier (2009). (2) Financial regulation depends heavily on credit ratings. Under the Standard Approach described in the "New Basel Capital Accord" the calibration of bank capital requirements to the risk of bank assets is based on credit ratings. ${ }^{1}$ (3) Banks increased leverage $^{2}$ and investment risk prior to the crisis. White (2010) argues that the inflated quality of credit ratings in the subprime market allowed banks to build excessive positions prior to the crisis when more pessimistic ratings would otherwise have allowed RCCR to prevent this. The potentially severe repercussions for the economic system of such a regulatory failure, partly due to ratings inflation, motivate a closer look at the optimal design of bank regulation.

An important contribution of this paper is to show that RCCR itself is a deep structural parameter in the sense of the Lucas (1976) critique. While becoming ever more reliant on credit ratings, bank regulation reduces the very incentives for honest information revelation by private agencies. Importantly, this result does not rely on costly information acquisition. RCCR incentivizes even a perfectly informed rating agency to inflate its ratings because the

\footnotetext{
${ }^{1}$ See BCBS (2006).

${ }^{2}$ According to BCBS (2009), the equity of large banks amounted to only $2 \%$ of their balance sheets by the beginning of the crisis in 2007 .
} 
agency makes money on every risky security that receives an inflated investment-grade rating. The key ingredient for this feature is an investor with an appetite for higher investment risk than is welfare-optimal. In this paper, a highly leveraged bank wants to increase asset risk to maximize shareholder value. As bank capital requirements are tied to the ratings of bank assets, ratings inflation relaxes regulatory constraints. ${ }^{3}$ In return for this regulatory relief banks pay higher prices for securities with investment-grade ratings. ${ }^{4}$ As only good ratings improve the terms on which issuers of securities can obtain funding, issuers only pay the rating agency for publishing good ratings. This incentivizes rating agencies to cater to the demand for regulatory relief.

Unlike in the extant literature, ratings inflation in this paper is not detrimental to society because it allows informational asymmetries between investors and issuers to persist. Instead ratings inflation decreases welfare because RCCR breaks down. As a consequence, banks do not simply underinvest in good risk types but additionally overinvest in bad risk types. This finding has important implications for the optimal design of regulation. If ratings inflation and excessive risk-taking prevail, the abolition of RCCR in favor of RICR increases welfare. RICR eliminates bank incentives for risk-shifting by setting a sufficiently low limit on bank leverage without relying on (potentially inflated) credit ratings. A potential drawback of RICR is that it can limit credit supply to borrowers with positive NPV projects if equity is the privately more expensive source of bank funding relative to debt. For this reason, welfare is maximized if the bank regulator maintains RCCR and at the same time implements mechanisms that discipline the rating agency to produce honest ratings.

The regulator's principal tool to discipline the rating agency is the threat to abandon RCCR in favor of RICR as soon as it finds out about ratings inflation and risk-shifting. Such a threat is credible as welfare is higher under RICR than under RCCR that suffers from collusion between rating and banking industry. The mere threat can already suffice to discipline the rating agency because an abolition of RCCR as mandated by the Dodd-Frank Act would entail a loss of future profits for the rating agency. If ratings stop providing the bank with a relief from regulatory constraints, the bank reduces its willingness-to-pay for securities with investment-grade ratings, which translates into a lower demand for ratings by issuers of securities. The trade-off between short-term benefits of ratings inflation and a

\footnotetext{
${ }^{3}$ The analysis applies also to other investors with binding portfolio constraints that are based on ratings. I thank Jean-Charles Rochet for pointing out that even individual fund managers with performance-linked convex renumeration schemes could welcome ratings inflation if they are restricted to hold a large part of the fund capital in securities with investment-grade ratings. Cantor et al. (2007) find that $75 \%$ in a survey of 200 pension plan sponsors and investment managers have such rating requirements.

${ }^{4}$ Kisgen \& Strahan (2010) find evidence that companies with low ratings have higher costs of capital.
} 
suffered loss of future revenues depends critically on the size of the latter.

A rational regulator predicts whether a rating agency optimally inflates its ratings and should choose between RICR and RCCR accordingly. However, one observes that agencies were not disciplined and did inflate ratings for structured debt prior to the crisis in 2007. Why then was regulation based on credit ratings and why did Hunt (2009) find that ratings played a role in at least 44 SEC rules as of June 2008? I argue that the trade-off between short-term revenues from ratings inflation and future rating profits varies over time. An agency could have been disciplined to produce honest ratings only at the time when RCCR was introduced but not some time afterwards. According to Gorton (2009), competition had driven down profitability in traditional areas of banking since the 1990s. The expansionary monetary policy after the dot.com bubble had further reduced interest rates and created a large demand for innovative securities offering high yields and investment-grade ratings. I show that varying incentives for risk-taking lead to varying incentives for ratings inflation. Consequently, the success of RCCR to prevent moral hazard is time-varying itself.

The paper also explores policy alternatives to RICR which try to restore the rating agencies' incentives. An increase in the civil liability of rating agencies ${ }^{5}$ or their loss of accreditation as NRSRO in the case of low ratings performance ${ }^{6}$ raise the expected costs of ratings inflation. However, the implementation of both policies meets practical and juridical difficulties. Pagano \& Volpin (2010) suggest the return to the investors-pay model but I show that this will simply allow banks to buy the ratings for their investment portfolios themselves, which facilitates their collusion with rating agencies. If the rating fees are not paid by individual institutions but paid from taxes, conflicts of interests will be eliminated but rating production will also become susceptible to political pressure.

The paper is organized into six sections: Section 2 discusses the contribution of this paper to the extant literature. Section 3 describes the model. I solve the model for RICR in Section 4 and for RCCR in Section 5, first considering the benchmark case with a benevolent rating agency and then repeating the exercise for an opportunistic private rater. Section 6 endogenizes the choice between RICR and RCCR and investigates regulation of rating agencies. Section 7 discusses limitations to the model and Section 8 concludes.

\footnotetext{
${ }^{5}$ The U.S. Justice Department has filed a lawsuit against S\&P in early 2013, accusing the agency of defrauding investors. The European Commission and the German Bundestag have passed motions to increase the civil liability of rating agencies, which would allow jurisdiction to hold raters liable if their ratings are shown to be inflated ex-post. See European Commission (2011) and Deutscher Bundestag (2011).

${ }^{6}$ Under the Dodd-Frank Wall Street Reform and Consumer Protection Act signed in 2010 the regulator can revoke an agency's accreditation as NRSRO. See US Congress (2010), Section 932. See also Stolper (2009) on the strategic approval of rating agencies.
} 


\section{Literature Contribution}

This paper addresses the question whether bank capital requirements should be calibrated to bank asset risk on the basis of credit ratings. Hellwig (2009) and Hellwig (2010) make the case against risk-calibration arguing that it allowed banks to be undercapitalized prior to the recent crisis. Admati et al. (2011) mandate more substantial risk-independent capital requirements explaining why bank equity is socially cheaper than bank debt. ${ }^{7}$ Deviations from the Modigliani \& Miller (1958) theorem can make equity the privately more expensive source of bank funding but mostly result from socially undesirable policies and could be resolved by political reform. Admati et al. (2012) explain why shareholders do not reduce leverage voluntarily if banks have already created debt overhang in the past.

This paper contributes to this debate about risk-calibration of capital requirements focusing on the role that credit ratings play for determining bank asset risk. To that end I introduce the conflicts of interests inherent in the credit rating industry into the central regulatory problem of risk calibration and asymmetric information. I find that regulated investors create incentives for ratings inflation. Calomiris (2009) presents empirical support for this finding.

Furthermore, this paper also extends research on credit rating agencies. Contrary to the extant literature, I do not focus on information production by rating agencies for investors but for a regulator. Regulation also plays a crucial role in the paper by Harris et al. (2013) who investigate the incentives of rating agencies to acquire costly information. But in their setting, the principle function of ratings remains to help uninformed investors better assess the risk-return properties of rated securities and to overcome adverse selection. I on the other hand isolate the regulatory function of ratings by shutting down informational asymmetries between the bank, issuers of securities, and the rating agency. This abstraction makes allowance for my assumption that informational asymmetries are more pronounced between regulators and the financial industry as a whole than within the financial industry. ${ }^{8}$ In my model (illustrated in Figure 1), the sole function of ratings is to help an uninformed regulator

\footnotetext{
${ }^{7}$ Numerous papers have analyzed alternatives to capital requirements as an instrument to reduce riskshifting in banking. For example John et al. (1991), Rochet (1992) and Giammarino et al. (1993) have researched optimal tax structures or risk-adjusted deposit insurance.

${ }^{8}$ Banks are more informed than regulators as they - unlike regulators - frequently invest and are supposed to have credit risk expertise. This should particularly be the case for structured finance products, which banks do not only buy but often also sell. According to He et al. (2011), there were always at least three banks among the top five issuers of MBS from 2000 to 2006. These top five issuers accounted for $38 \%$ to $47 \%$ of all the newly issued securities. Brunnermeier et al. (2009) report that banks were also among the most active buyers of structured products.
} 


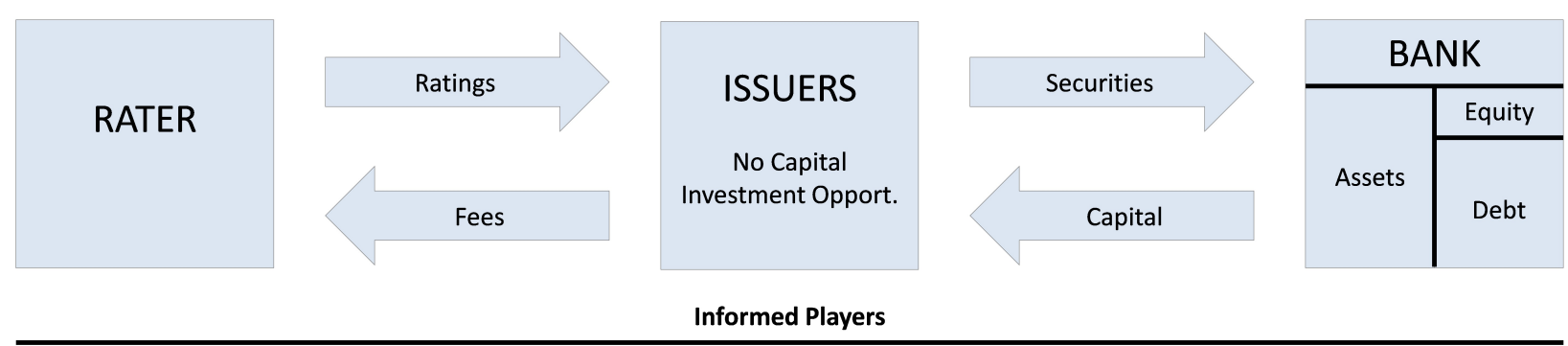

Uninformed Players
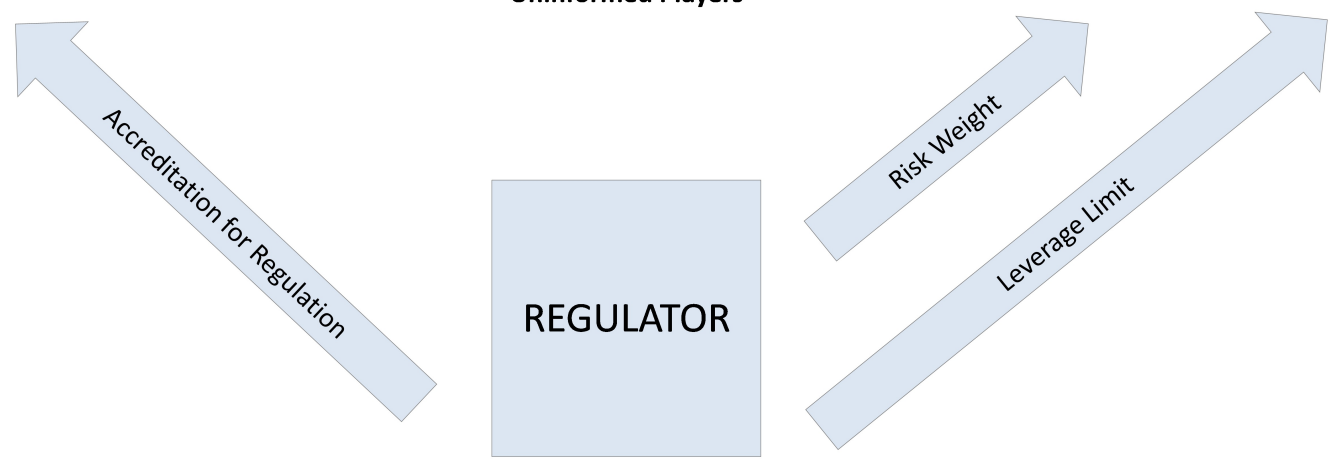

Figure 1: Institutional framework: Strategic relationships between the informed financial industry (top) and the uninformed regulator (bottom).

to calibrate bank capital requirements to bank asset risk. To my knowledge, this is the first paper to focus on this regulatory function of ratings.

Whereas the purpose of this paper is normative, the analysis of Harris et al. (2013) is positive in the sense that they take regulatory distortions as given. I on the other hand endogenize how regulation augments the benefit of investment-grade ratings and model the strategic relationships between bank regulator, rating agency and bank explicitly.

This paper also links up to empirical work on the regulatory benefit of credit ratings. Brister et al. (1994) find evidence that the high yield premium of speculative bonds contains an effect of regulation. Chen et al. (2012) use the redefinition of eligibility of split-rated bonds in the Lehman Brothers bond indices in 2005 to show that investment-grade ratings carry additional benefits not related to their informational content. Hau et al. (2013) confirm that "larger and more leveraged banks receive systematically more favorable credit ratings."

Finally, this paper provides a new perspective on ratings inflation that can arise because institutional investors (banks) demand high-yield investments with inflated ratings and have incentives to collude with rating agencies. This contrasts with the prediction of Bolton et al. (2012) that investors will lose out if ratings are biased. In their model agencies deliberately inflate their ratings to attract business if they can fool a sufficiently large group of investors. 
Ratings inflation occurs because trusting investors do not understand the rater's incentives to collude with risky issuers. Although not trusting, investors in Mathis et al. (2009) are still unable to back out the informational content of ratings and can hence be deceived. By contrast, the investor in this paper (the bank) is sophisticated and fully informed but still generates incentives for ratings inflation because bank regulation is tied to credit ratings. ${ }^{9}$

A number of papers explains ratings inflation with the fact that issuers can suppress noisy ratings (for example, Mählmann, 2008; and Faure-Grimaud et al., 2009). In Skreta \& Veldkamp (2009), sufficiently noisy information production conveys ratings shopping and ratings bias prevails even if agencies rate to the best of their knowledge. ${ }^{10}$ In none of these papers do investors actually profit from ratings inflation, as does the bank in my model.

\section{Model}

\section{Assumption 1: Bank.}

A risk-neutral bank maximizes the expected payoff to its shareholders over its investment portfolio and its capital structure:

(a) Investment opportunities

The bank allocates a share of capital $x \in[0,1]$ to a risky issuer and a share $1-x$ to a risk-free issuer. Both issuers possess perfectly divisible investment opportunities with constant returns to scale. The risk-free investment returns $R_{f}$ with probability one for each unit of capital invested, whereas the risky investment returns $R>R_{f}$ only with probability $p$. The risk-free (risky) investment has a positive (negative) NPV like in Holmstrom $\& 5$ Tirole (1997) or in Harris et al. (2013). Issuer types and cash flows are verifiable by the bank.

(b) Capital structure

The bank has equity $E$ and collects deposits $D \in[0, S] . S$ is the maximal amount of deposits supplied to a bank with equity E. The depositors require only a gross return of 1 because of deposit insurance.

\footnotetext{
${ }^{9}$ In Harris et al. (2013), investors price the risk of buying a security with an inflated rating such that ratings inflation does not hurt them ex-ante. But ex-post, once the purchase has been effectuated, investors are strictly better off if they were lucky to have bought a low-risk security with an unbiased credit rating.

${ }^{10}$ See also Sangiorgi et al. (2009) and Poon \& Firth (2005) on ratings shopping.
} 
The risk-free and the risky issuer possess only their investment opportunities. Both enjoy limited liability and therefore even an issuer with the risky negative NPV project will apply for funding. The bank is the issuers' only source of funding and captures the complete return from the issuers' investments.

As in Adrian \& Shin (2012) the two investment types have constant returns to scale. Investment is only limited by bank equity $E$ and the maximal supply $S$ of deposits. The depositors cannot buy securities directly from issuers nor do they monitor the bank's risk choices as the state insures bank debt. This elimination of market discipline potentially generates a welfare reduction because the bank can make riskier investments if depositors do not monitor. Whereas I do not specify the design of the public bail-out guarantee for bank debt, the potential welfare costs in the form of riskier bank investment enter the optimization problem of the regulator as I will discuss later. As bank debt is insured by the state, I normalize the required gross return to deposits to 1 which could, for example, reflect an outside-option to store cash at home at zero cost.

The issuance of new bank debt or equity is not modeled as the total amount of bank capital only scales the size of the economy. In Equation (1) I make an assumption only about the relative amounts of equity $E$ and available deposits $S$ to guarantee that the bank can lever up sufficiently high to have risk-shifting incentives. For the same reason, I assume in Equation (2) that the expected return to bank shareholders on one unit of deposits is higher if it is allocated to the risky issuer than if it is allocated to the risk-free issuer $\left(\mathbb{E}[\max \{R-1,0\}]>R_{f}-1\right)$.

\section{Assumption 2: Excessive risk-taking.}

The parameters satisfy the following inequalities:

$$
\begin{gathered}
S>E \cdot \frac{R_{f}-p \cdot R}{p \cdot(R-1)-\left(R_{f}-1\right)} \\
p \cdot(R-1)>R_{f}-1
\end{gathered}
$$

There are no conflicts of interests between bank management and bank shareholders and the bank maximizes the expected payoff to shareholders. The objective function is

$$
\max _{x, D} \mathbb{E}\left[\pi_{B}(D, x)\right], \text { where } \pi_{B}(D, x)=\max \left\{(E+D) \cdot\left[(1-x) \cdot R_{f}+x \cdot \tilde{R}\right]-D, 0\right\}
$$




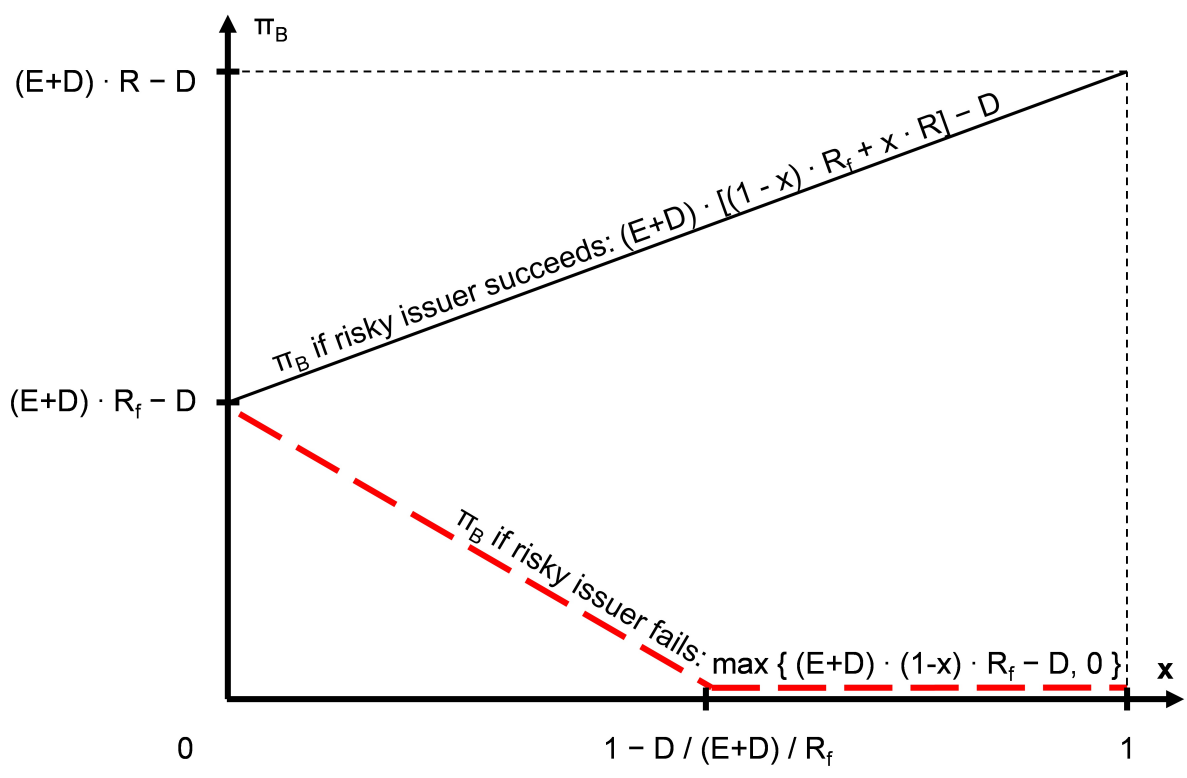

Figure 2: Bank shareholder payoff conditional on the success of the risky issuer: The solid (dashed) line represents the shareholders' payoff $\pi_{B}$ in $t=1$ for different bank portfolios $x$ conditional on the success (failure) of the risky issuer.

$\pi_{B}$ denotes the shareholders' payoff in $t=1$ and $\tilde{R}$ with a tilde denotes the random return to the risky security with possible realizations 0 and $R .^{11}$ The shareholders' payoff $\pi_{B}$ is convex for positive $D$ provided that $x$ is sufficiently large. Figure 2 illustrates this point. The solid line graphs the shareholder payoff conditional on the success of the risky issuer for different portfolios $x$. The dashed line shows the shareholder payoff conditional on a failure. For $x \in\left(1-\frac{D}{E+D} \cdot \frac{1}{R_{f}}, 1\right]$, shareholders enjoy the upside potential of the risky investment whereas limited liability protects them from negative payoffs if the risky issuer should fail. Losses are socialized as the state compensates depositors for whatever the bank fails to repay.

It will prove useful for the exposition of the solution to note that the bank never chooses $x \in\left(0,1-\frac{D}{E+D} \cdot \frac{1}{R_{f}}\right]$ because on that interval losses from a negative NPV investment are fully absorbed by equity. Furthermore, if for some reason the bank chooses $x>1-\frac{D}{E+D} \cdot \frac{1}{R_{f}}$, it minimizes its position in the risk-free issuer because for $x>1-\frac{D}{E+D} \cdot \frac{1}{R_{f}}$ the shareholders' payoff increases in $x$ conditional on the success of the risky issuer whereas it is independent of $x$ conditional on a failure.

Lemma 1. The bank optimally either maximizes or minimizes investment risk and chooses between $x=0$ and the highest $\bar{x}$ that regulation allows.

\footnotetext{
${ }^{11}$ Under RCCR, the objective function (3) will be affected by rating fees (see Equation (14)).
} 
Proof: Omitted.

\section{Assumption 3: Regulator.}

The regulator maximizes welfare $W$ defined as the expected net return to overall investment. The regulator can verify neither issuer types nor returns accruing to the bank. ${ }^{12}$ It chooses between two regulatory regimes:

(a) Rating-independent capital regulation ( $R I C R$ )

The regulator maximizes $W$ over an upper limit $\bar{D} \in[0, S]$ on bank deposits $D$ :

$$
\begin{gathered}
\max _{\bar{D} \in[0, S]} W\left(D^{*}(\bar{D}), x^{*}(\bar{D})\right) \\
\text { where }\left(x^{*}(\bar{D}), D^{*}(\bar{D})\right)=\underset{x, D}{\operatorname{argmax}} \mathbb{E}\left[\pi_{B}(D, x)\right] \text { s.t. } D \leq \bar{D} .
\end{gathered}
$$

(b) Rating-contingent capital regulation ( $R C C R$ )

The regulator maximizes $W$ over the risk-weight $w>\frac{E}{E+S}$ on a bank investment without an investment-grade rating. The risk-weight on a bank investment with an investmentgrade rating is normalized to zero.

$$
\begin{gathered}
\max _{w} W\left(D^{*}(w), x^{*}(w)\right) \\
\text { where }\left(x^{*}(w), D^{*}(w)\right)=\underset{x, D}{\operatorname{argmax}} \mathbb{E}\left[\pi_{B}(D, x)\right] \text { s.t. } E \geq x \cdot(E+D) \cdot w .
\end{gathered}
$$

Provided that correct ratings inform the regulator about the risk types of different bank assets, the regulator can penalize the risky portfolio position of the bank with a capital charge. Bank equity must exceed the risky investment $x \cdot(E+D)$ times risk-weight $w$. I restrict the attention to the regulated case in which $w$ is set high enough to constrain the bank's optimization problem:

$$
E<(E+S) \cdot w
$$

If (8) was not satisfied, bank equity would exceed risk-weighted assets even for highestpossible leverage and complete allocation of all capital $E+S$ to the risky investment.

\footnotetext{
${ }^{12}$ The way to think about this is that the difference $R-R_{f}$ is for example due to a private benefit of investing in a risky issuer (see Holmstrom \& Tirole, 1997) or due to an intermediation cost of investing in the risk-free issuer which is unknown to the regulator.
} 
The regulatory constraint in (7) defines a maximum share of capital $\bar{x}(w, D)$ that regulation allows the bank to allocate to the risky investment and can be rewritten as

$$
x \leq \bar{x}(w, D):=\min \left\{\frac{E}{(E+D) \cdot w}, 1\right\} .
$$

According to Inequality (9), higher values of $w$ and deposits $D$ force the bank to invest less in the risky investment. RCCR constrains the bank's portfolio choice through the risk weight. Because of asymmetric information the regulator cannot determine if the bank respects the regulatory constraint (9) and thus requires a rating agency to identify risk types for it.

\section{Assumption 4: Rating agency.}

The rating agency (henceforth called the rater) perfectly observes risk types. It produces $A$ and B-ratings. An A-rating (B-rating) states that an investment is risk-free (risky). The rater maximizes its expected payoff over two decision variables:

(a) Binary decision variable $T$.

Variable $T$ stands for truthtelling. For $T=1$, the rater attributes rating $A$ to the risk-free and rating $B$ to the risky issuer. For $T=0$, the rater inflates/pools ratings attributing the A-rating to both issuers. ${ }^{13}$

(b) Publishment fee $f$.

The rater sets fee $f$ that an issuer must pay per unit of capital received from the bank if the issuer decides to publish the rating. An issuer with a B-rating never publishes its rating and does not pay $f$.

If the regulator finds out that $T=0$, it abandons $R C C R$ and the rater loses future $R C C R$ contingent income $P$.

As in Stolper (2009), the rater has free access to error-free information. This assumption eliminates the case in which the rater inflates ratings simply because honest information production is too expensive. I will show how incentives to inflate ratings arise despite free access to information if raters can participate in the incremental revenues from selling ratinginflated debt to a regulated bank. ${ }^{14}$ The assumption of perfect informational symmetry

\footnotetext{
${ }^{13}$ The rater never gives the $B$-rating to both issuers as the risk-free issuer would not pay for publishing it.

${ }^{14}$ By contrast, in Harris et al. (2013), free information acquisition implies that "the rating agency would always acquire and publish a perfect signal and rating inflation would not occur" (p. 48).
} 
between raters and other players inside the financial industry lays the focus on the regulatory function of credit ratings.

I consider only solicited ratings for which the issuers decide whether they are distributed to investors. ${ }^{15}$ An issuer only pays the rater if the rating is published. This is consistent with the report of the Securities and Exchange Commission (SEC) that "typically, the rating agency is paid only if the credit rating is issued, though sometimes it receives a breakup fee for the analytic work undertaken even if the credit rating is not issued."16 Issuers are assumed to publish only $A$-ratings as $B$-ratings do not improve lending terms. As in Hirth (2012), this simplification should be understood as a reduced-form model of ratings shopping which has been extensively analyzed in the extant literature (see Section 2). ${ }^{17}$ As the issuers never publish $B$-ratings, publishment fee $f$ can be interpreted as the relative value of an $A$ - to a $B$-rating. A positive value of $f$ represents a regulatory relief or benefit of investment-grade ratings for regulated investors and is determined endogenously. ${ }^{18}$

The $A$-rated issuer pays publishment fee $f$ per unit of capital received from the bank. ${ }^{19}$ This is consistent with two observations: (1) The size of an issue is likely to correlate with the fees negotiated between rater and issuer. (2) Firms tend to sell more than just one security. Interpreting each unit of capital borrowed as the price of one security, $f$ is the fixed fee for publishing the rating of each single security. ${ }^{20}$

Given these assumptions, the objective function of the opportunistic rater follows as:

$$
\max _{T, f} \mathbb{E}\left[\pi_{R A}(w, T, f)\right]= \begin{cases}(E+D) \cdot(1-x) \cdot f, & \text { if } T=1 \\ (E+D) \cdot f-(1-p) \cdot P, & \text { if } T=0\end{cases}
$$

For $T=1$ the rater gets fees only for the share $(1-x)$ of bank capital that is lent to the risk-free type. For $T=0$ the rater gets fees for both the risky and the risk-free investment.

\footnotetext{
${ }^{15}$ According to Sangiorgi et al. (2009), unsolicited ratings are rare in practice.

${ }^{16}$ Securities and Exchange Commission (SEC) (2008), p.9. See Bolton et al. (2012) for a model that incorporates a small breakup fee paid in addition to the publishment fee.

${ }^{17}$ Norman Schürhoff asked if the risk-free issuer would not hold back its $A$-rating if $T=0$ thereby signaling the regulator that the risk-weight should be applied to the $A$-rated bank assets. However, I model a sequential game in which the regulator sets the risk-weight before the other players choose their strategies. This is consistent with reality as regulatory frameworks usually change only in intervals of several years. In such a setting the risk-free issuer optimally publishes its $A$-rating as holding it back would only result in a loss of preferential regulatory treatment.

${ }^{18}$ In Harris et al. (2013), the regulatory benefit of $A$-ratings is introduced as an exogenous parameter.

${ }^{19}$ Alternatively, I could assume a volume-independent fee. As the rater could set this fixed fee equal to $f$ times the investment volume, the results would not change.

${ }^{20}$ Finally, one might also assume a continuum of issuers. Issuers of the same type possess identical (perfectly correlated) investment opportunities of size 1 and must each pay $f$ for publishing a rating.
} 
For $T=0$ the rater puts future RCCR-contingent revenues $P$ at risk. The regulator finds out about ratings inflation if the $A$-rated risky issuer defaults with probability $1-p$ because only the risky issuer can default. ${ }^{21}$ As I show later, welfare is negative under RCCR for $T=0$ because the bank finances the negative NPV project. The regulator optimally abandons RCCR in favor of RICR, ratings lose their regulatory advantage for the bank and the rater loses future RCCR-contingent income $P$. This feature is consistent with current regulatory reform. For example, the Dodd-Frank Act mandates the elimination of rating-contingent regulation-likely on account of the massive downgradings and defaults of structured finance products from 2007 to 2009. To simplify the analysis, I follow Bolton et al. (2012) in introducing $P$ as an exogenous parameter. ${ }^{22}$

\section{Assumption 5: Bargaining power of rater.}

(a) For $T=1$, publishment fee $f$ is bound by $\bar{f} \in\left[0,1-\frac{1}{R_{f}}\right]$.

(b) For $T=0$, publishment fee $f$ is bound by the highest fee that still satisfies:

$$
\mathbb{E}\left[\pi_{B}(T=0, f] \geq \mathbb{E}\left[\pi_{B}(T=1, f)\right]\right.
$$

I model the rater's market power to extract fees in reduced form assuming an absolute upper bound $\bar{f}$ on the fee $f$ that the rater can charge conditional on $T=1$. For example, for $\bar{f}=1-\frac{1}{R_{f}}$ the risk-free return net of fees is $(1-\bar{f}) \cdot R_{f}=1$. The rater is able to claim the entire return to the $A$-rated security. For an even higher fee, the bank would be better off not investing at all. By contrast, for $\bar{f}=0$ the rater cannot charge any fees.

The rater's power to extract fees conditional on ratings inflation $(T=0)$ is restricted by requirement (11) that the bank shareholders must earn an expected payoff, which is at least as high as the payoff they would earn if the rater rated truthfully and set $T=1$. I stress that this assumption works against ratings inflation. It potentially prevents ratings inflation in cases in which ratings inflation would have prevailed if the rater had chosen $f$ and $T$ without respect for $(11){ }^{23}$

\footnotetext{
${ }^{21}$ The identification of rating bias is difficult in practice as even low-risk assets are rarely completely risk-free and default does thus not necessarily imply a misspecified investment-grade rating. Therefore, the identification rule for ratings inflation would have to look at the average default rate in large groups of securities that carry the same rating.

${ }^{22}$ In Bolton et al. (2012), the investors themselves - not the regulator-punish the rater when the default of an $A$-rated project reveals ratings inflation.

${ }^{23}$ The way to think about Inequality (11) is that the bank could, for example, threaten the rater that it
} 


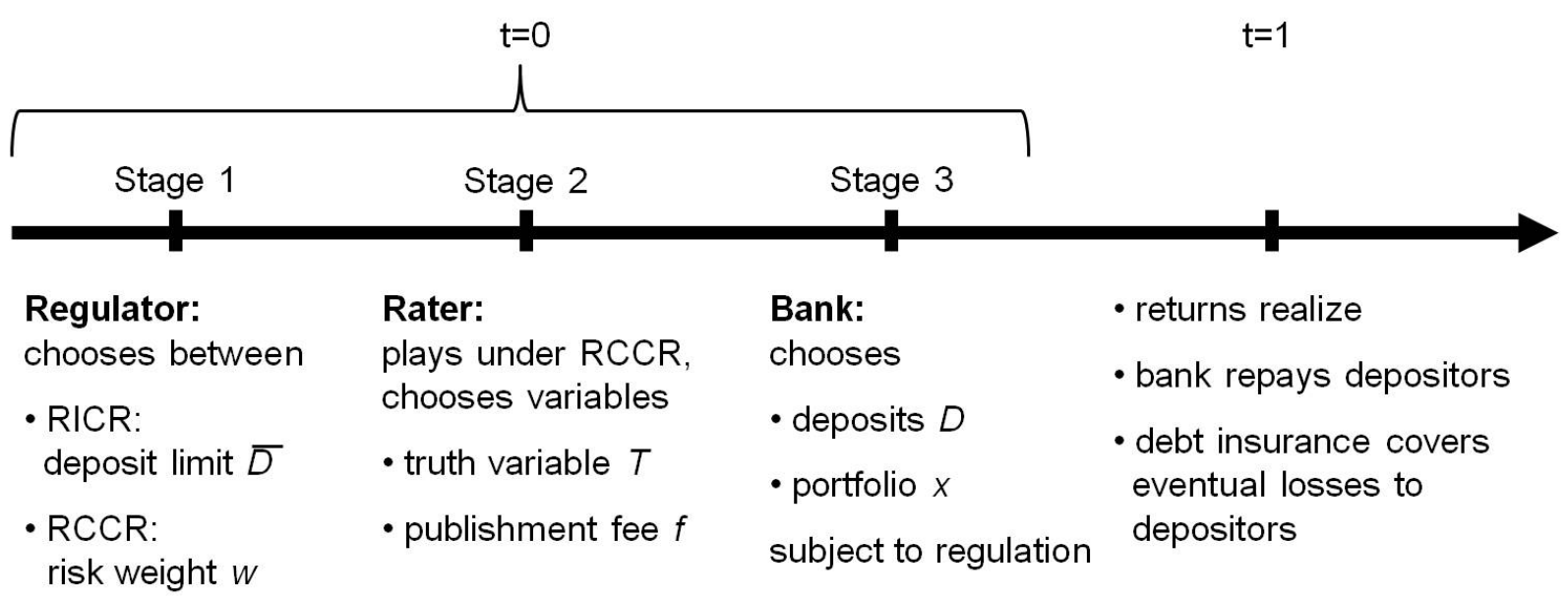

Figure 3: Game sequence: In $t=0$ the regulator chooses between RICR and RCCR. Depending on this choice, it sets leverage limit $\bar{D}$ or risk weight $w$. Provided that the regulator has chosen $\mathrm{RCCR}$, the rater decides whether to produce truthful ratings $(T=1)$ or to inflate ratings $(T=0)$ and sets publishment fee $f$. Finally, the bank collects an amount of deposits $D$ and chooses investment portfolio $x$ subject to regulatory constraints. In $t=1$ the returns realize and payments between issuers, bank, depositors and potentially debt insurance are effectuated.

\section{Rating-Independent Bank Capital Regulation}

The general game sequence is shown in Figure 3. In $t=0$ the regulator plays first and chooses between RICR and RCCR. To begin, I analyze the game conditioning on RICR. In that case, the regulator sets the upper limit $\bar{D} \in[0, S]$ on the amount of deposits that the bank is allowed to collect. Stage 2 is omitted as the rater does not play under RICR. The bank collects deposits $D \in[0, \bar{D}]$, lends the share $x \in[0,1]$ of its capital to the risky issuer and the share $1-x$ to the risk-free issuer. In $t=1$ the returns realize and the two issuers fulfill their obligations to the bank if they were successful and the bank repays the deposits. If the bank cannot service all its debt obligations, the state steps in and pays the depositors the difference.

Lemma 2. If the deposits $D \in[0, \bar{D}]$ exceed the threshold $D_{t h r}^{I}$, then the bank allocates $E+D$ to the risky inefficient issuer $\left(x^{*}=1\right)$. Otherwise, it allocates $E+D$ to the risk-free issuer $\left(x^{*}=0\right)$. The threshold is $D_{t h r}^{I}:=E \cdot \frac{R_{f}-p \cdot R}{p \cdot(R-1)-\left(R_{f}-1\right)}$.

will inform the regulator about ratings inflation. The regulator would have no reason to disbelieve the bank as the bank would be reporting an upward bias whose correction by the regulator would tighten regulation. However, in the case $T=1$ the regulator would not believe the bank if it reported a downward bias as the regulator knows about the bank's risk-shifting incentives. 
The convexity of the shareholders' payoff (3) increases in collected deposits $D$ provided that the bank invests all in the risky issuer $(x=1)$. For $D>D_{t h r}^{I}$, the value transferred from depositors to shareholders $D \cdot\left[p \cdot(R-1)-\left(R_{f}-1\right)\right]$ exceeds the expected loss $E$. $\left(R_{f}-p \cdot R\right)$ from investing equity $E$ in the project with negative NPV. For $D \leq D_{t h r}^{I}$ on the other hand, the shareholder payoff for $x=0$ exceeds the expected shareholder payoff for $x=1$ as shown in the top plot of Figure 4 . Therefore, the bank takes excessive risk $(x=1)$ only for $D>D_{t h r}^{I}{ }^{24}$

According to Figure 4, the expected shareholder payoff strictly increases in $D$ for $x=0$ as well as for $x=1$. Therefore, the bank optimally saturates the regulatory constraint choosing $D^{*}=\bar{D}$. Whether the bank takes excessive risk and welfare is negative then depends on the regulator's choice of limit $\bar{D} \cdot{ }^{25}$ As welfare is positive and increasing for $\bar{D} \leq D_{t h r}^{I}$ but negative and decreasing thereafter (see bottom plot of Figure 4), welfare is maximized for $\bar{D}^{*}=D_{t h r}^{I}{ }^{26}$

$$
W\left(\bar{D}, D^{*}, x^{*}\right)=\left\{\begin{array}{cc}
(E+\bar{D}) \cdot(p \cdot R-1)<0, & \text { if } \bar{D}>D_{t h r}^{I} \\
(E+\bar{D}) \cdot\left(R_{f}-1\right)>0, & \text { if } \bar{D} \leq D_{t h r}^{I}
\end{array}\right.
$$

Proposition 1. Under RICR there exists a unique equilibrium in which

1. the regulator imposes a low limit on the amount of debt that the bank is allowed to collect for given equity: $\bar{D}^{*}=D_{t h r}^{I}$.

2. the bank collects as many deposits as regulation allows $D^{*}=D_{t h r}^{I}$ and allocates all capital to the risk-free issuer $\left(x^{*}=0\right)$.

3. welfare is larger than in the unregulated case $(\bar{D} \geq S)$ and positive:

$$
W\left(D_{t h r}^{I}, x^{*}=0\right)=\left(E+D_{t h r}^{I}\right) \cdot\left(R_{f}-1\right) .
$$

Proof: Omitted.

\footnotetext{
${ }^{24}$ An interior solution in which the bank invests only part of its equity and debt into one project type and the rest into the other type is never optimal (see Lemma 1 ).

${ }^{25}$ In the absence of any regulation, the bank would take excessive risk because the supply of deposits $S$ exceeds the threshold $D_{t h r}^{I}$ according to Inequality (2).

${ }^{26}$ For $D=D_{t h r}^{I}$, the bank is indifferent between $x=0$ and $x=1$ and I assume that the bank invests all into the risk-free project. This assumption is uncritical as the regulator can choose a leverage limit that falls short of $D_{t h r}^{I}$ by a small positive $\epsilon$ close to zero.
} 

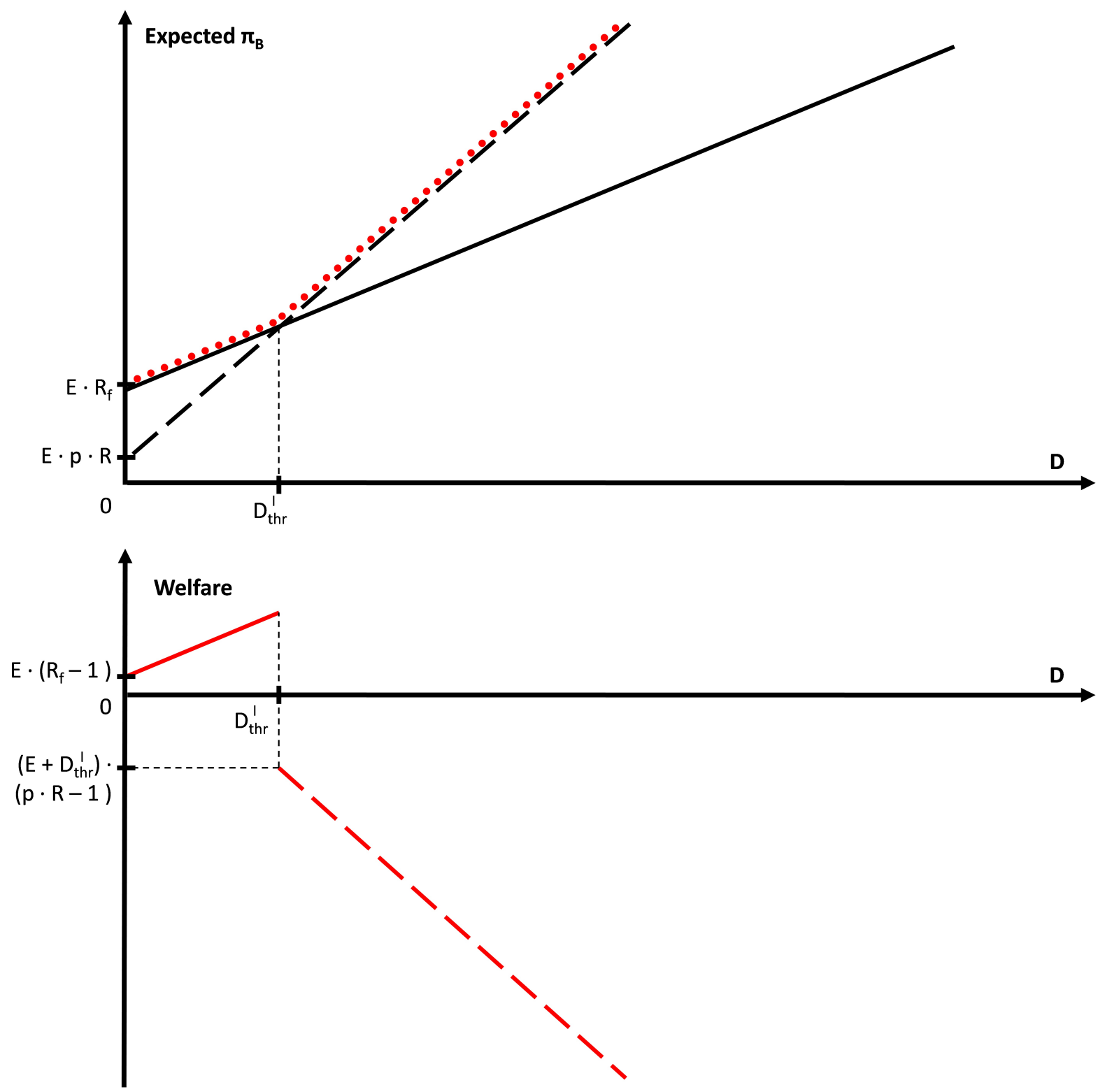

Figure 4: Expected payoff to shareholders and welfare under RICR: Top plot: Expected shareholder payoff in $t=1$. The solid line represents the shareholder payoff if all equity and debt are allocated to the risk-free investment $(x=0)$. The dashed line represents the expected shareholder payoff if everything is allocated to the risky investment $(x=1)$. The dotted line represents the expected payoff to shareholders when the bank chooses the optimal investment portfolio $x^{*}(D)$ conditional on the amount of debt $D$. Bottom plot: Welfare when the bank chooses $x^{*}(D)$ optimally conditional on $D$. 


\section{Rating-Contingent Bank Capital Regulation}

I analyze RCCR whose success at preventing excessive risk-taking depends on the willingness of the private rater to create informational symmetry between regulator and financial industry. In Subsection 5.1, I derive the equilibrium in the benchmark case in which a benevolent rater never biases its ratings $(T=1)$. In Subsection 5.2, I analyze the optimal behavior of an opportunistic rater that only tells the truth if doing so maximizes its profit.

\subsection{Benevolent Rater}

In the benchmark case, the rater attributes its $A$-rating to the risk-free and its $B$-rating to the risky issuer. Only an issuer with an $A$-rating publishes its rating. As Figure 3 shows, the regulator plays first, setting the risk-weight $w$ for the risky investment without an $A$-rating. Then the rater chooses the fee $f$ that an issuer pays per unit of capital received from the bank for publishing its rating. Finally, the bank collects deposits $D$ and chooses its portfolio allocation $x$. I solve the model backwards starting with the bank, which maximizes the expected shareholder payoff subject to the regulatory constraint (9):

$$
\begin{gathered}
\max _{D, x} \mathbb{E}\left[\pi_{B}(f, D, x)\right] \text { s.t. } x \leq \bar{x}(w, D), \quad \text { where } \\
\pi_{B}(D, x)=\max \left\{(E+D) \cdot\left[(1-x) \cdot(1-f) \cdot R_{f}+x \cdot \tilde{R}\right]-D, 0\right\}
\end{gathered}
$$

The shareholder payoff $\pi_{B}$ slightly differs from its definition in (3). Under RCCR the bank must accept a lower risk-free yield $(1-f) \cdot R_{f}<R_{f}$ because the risk-free issuer must finance fees for the $A$-rating and cannot invest everything into its risk-free project.

According to Lemma 1, the optimal portfolio allocation $x^{*}$ is either $x=0$ or the highest position in the risky issuer that RCCR allows $(x=\bar{x})$. The top plot of Figure 5 shows the expected shareholder payoffs for $x=0$ (solid line) and $x=\bar{x}$ (dashed line) conditional on collected deposits $D$. One can distinguish three different intervals:

1. For $D \geq D_{t h r}^{I I I}$, expected shareholder payoff is maximized if the bank allocates all capital to the risk-free issuer with the $A$-rating $(x=0)$. Surprisingly, no excessive risk-taking occurs for high leverage. The reason is that the regulatory constraint $x \leq \bar{x}$ tightens as leverage increases because the maximum position $\bar{x}(w, D)$ that regulation allows the bank to invest in the issuer without the $A$-rating decreases in $D$. Regulation limits the upside potential of the bank's portfolio for large leverage and the bank is better off allocating all its capital to the risk-free issuer. 


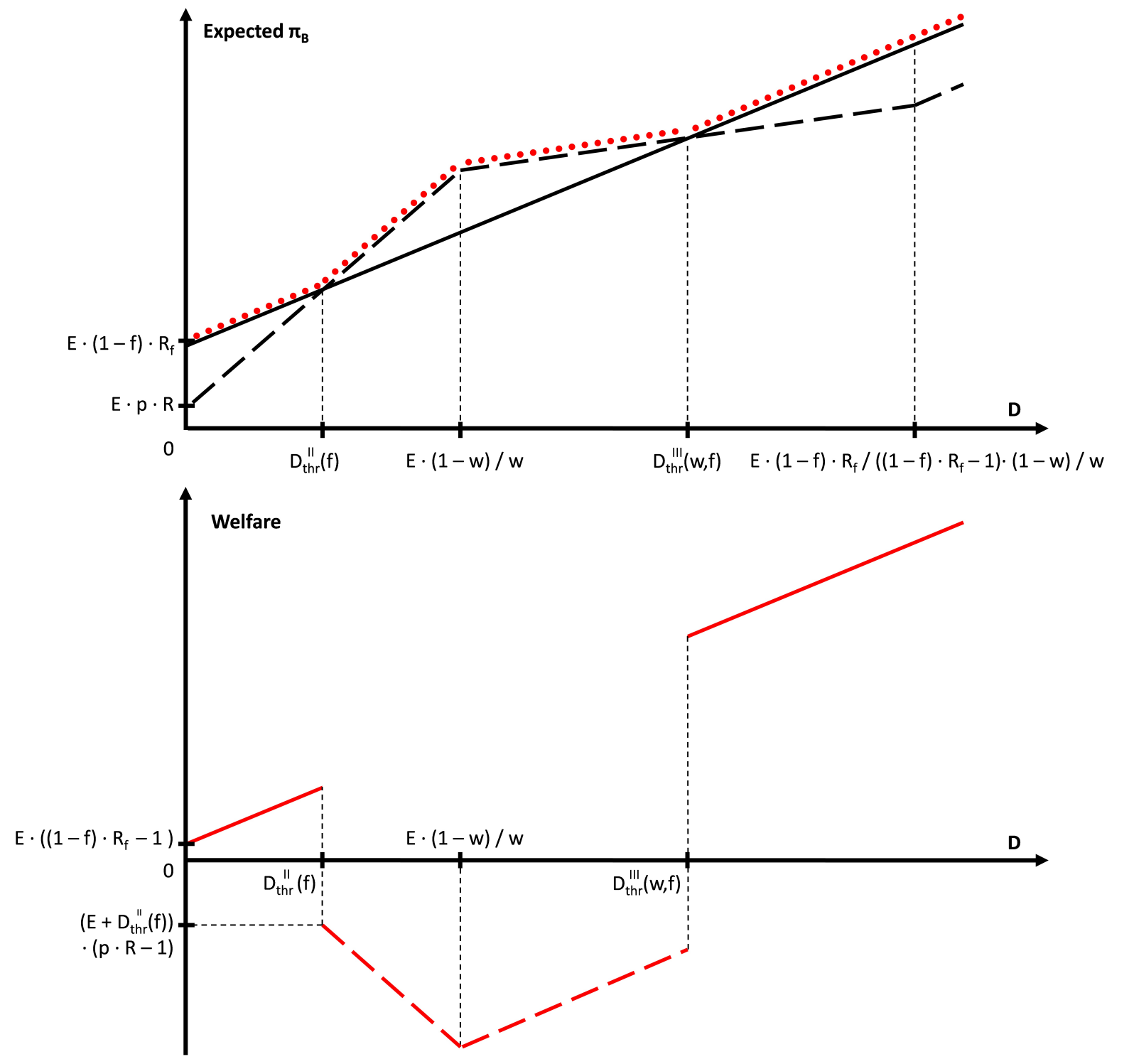

Figure 5: Expected payoff to shareholders and welfare under RCCR with a benevolent rater: Top plot: Expected shareholder payoff in $t=1$. The dashed line represents the bank's expected shareholder payoff when the regulatory maximum $\bar{x}(w, D)$ is allocated to the risky inefficient issuer. The solid line represents the bank's expected shareholder payoff when all capital is allocated to the risk-free efficient project $(x=0)$. The red dotted line represents the expected shareholder payoff when the bank chooses the optimal portfolio $x^{*}(D)$ conditional on the amount of debt $D$. Bottom plot: Welfare when the bank chooses $x^{*}(D)$ optimally conditional on $D$. 
2. For $D \leq D_{t h r}^{I I}$, expected shareholder payoff is maximized for $x=0$, too. Similar to Section 4, for low leverage, bank shareholders suffer more from investing their equity into the issuer with negative NPV than they would gain from gambling with the money of their depositors.

3. For $D \in\left(D_{t h r}^{I I}, D_{t h r}^{I I I}\right)$, expected shareholder payoff is maximized for $x=\bar{x}$. Leverage and therefore the convexity of the shareholders' claim are large enough that investment in the risky issuer with negative NPV is optimal. At the same time, leverage is sufficiently low that the regulatory constraint (9) does not limit the upside potential of the most risky portfolio that regulation permits by too much.

According to Figure 5, the expected shareholder payoff increases in $D$ for $x=0$ as well as for $x=\bar{x}^{27}$ Therefore, the bank optimally collects all supplied deposits $\left(D^{*}=S\right)$. Whether the bank takes excessive risk depends on the location of $S$ relative to $D_{t h r}^{I I I}(w, f)$ which decreases in the risk-weight $w$ but increases in fee $f$ as demonstrated in Figure $6 .{ }^{28}$ If $w$ is large, then the regulatory constraint (9) is tight and excessive risk-taking $(x=\bar{x}(w, D))$ is optimal only for a relatively small range of leverage values. If the risk-free issuer must finance high fees $f$, then the risk-free return to the bank $(1-f) \cdot R_{f}$ is small and excessive risk-taking is more attractive for a relatively large range of leverage values. Taken together, the bank takes excessive risk $(x=\bar{x})$ if $w$ is low and $f$ is high.

Before the bank chooses its financing and investment policy, the benevolent rater maximizes its payoff over fee $f$ conditional on risk-weight $w$ :

$$
\max _{f} \pi_{R A}(w, f)=(E+S) \cdot\left(1-x^{*}(w, f)\right) \cdot f
$$

The fee $f$ has two opposing effects on the rater's payoff. First, raising $f$ increases the fee that the rater receives for each unit of the $A$-rated security that is sold to the bank. On the other hand, raising $f$ potentially lowers the bank's demand $(E+S) \cdot\left(1-x^{*}(w, f)\right)$ for the $A$-rated security. If $f$ exceeds some threshold $f_{t h r}^{(T=1)}$, then $D_{t h r}^{I I I}(w, f)$ exceeds $S$ and the bank allocates as much capital as regulation allows from the risk-free issuer with the

\footnotetext{
${ }^{27}$ For very high rating fees, the expected payoff to bank shareholders from the portfolio $x=0$ would actually be decreasing in $D$. However, as shown later, the rater never chooses such a high fee.

${ }^{28}$ It can be shown that the lower threshold $D_{t h r}^{I I}$ is smaller than $D_{t h r}^{I}$ for all $w, f$. By Assumption 2 and Inequality (2) the supply of deposits $S$ hence exceeds $D_{t h r}^{I I}$.
} 

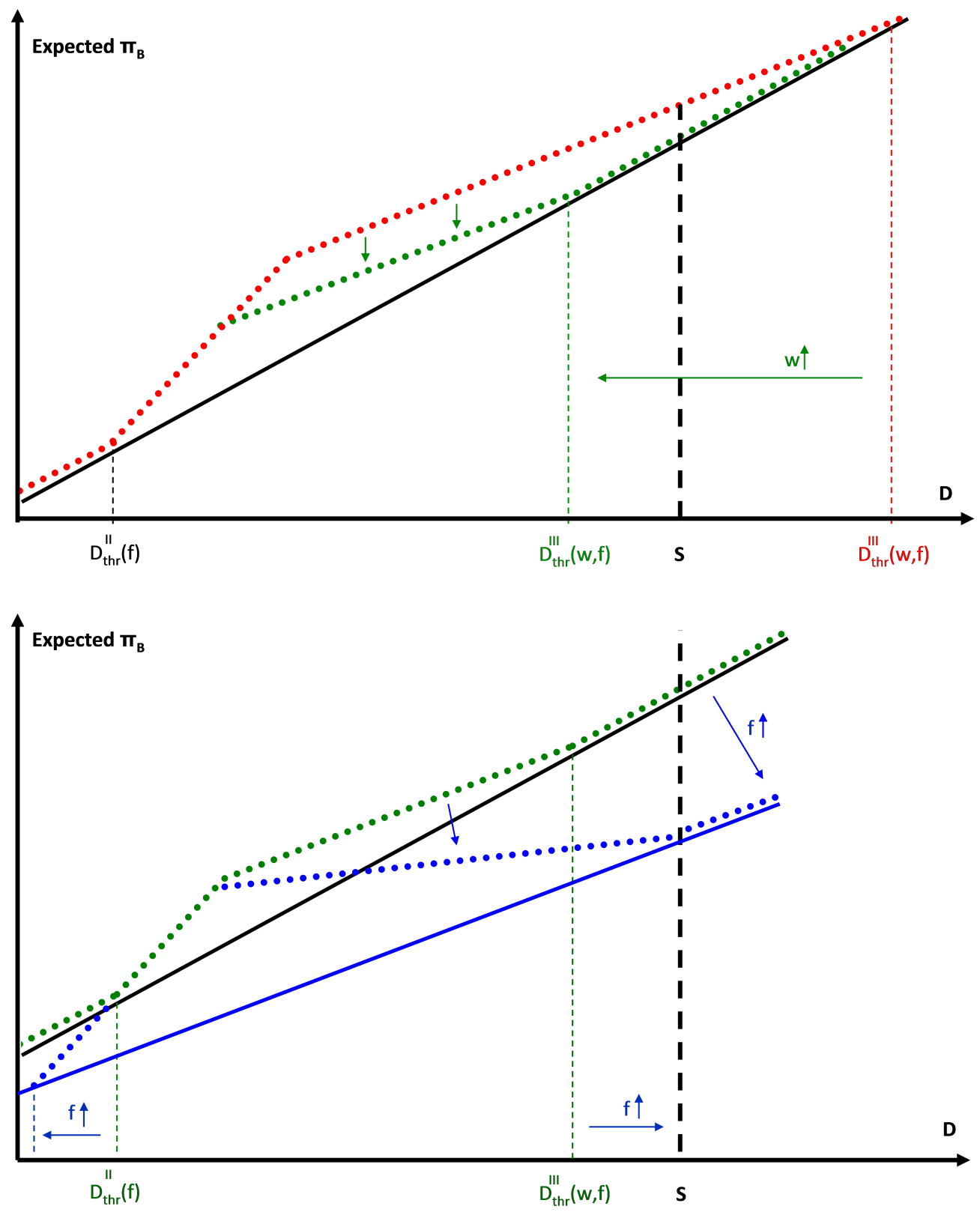

Figure 6: Comparative statics under RCCR with a benevolent rater: The solid lines represent the payoff to bank shareholders when all capital is allocated to the risk-free project $(x=0)$. The dotted lines represent the expected payoffs when the bank chooses the optimal portfolio $x^{*}(D)$ conditional on the amount of debt $D$. Top plot: The dotted line shifts inwards as the risk-weight $w$ increases ceteris paribus. Bottom plot: The solid line shifts downwards as fee $f$ increases. The slopes of the solid line and on $\left(E \frac{1-w}{w}, \infty\right)$ also the slope of the dotted line decrease as $f$ increases. 

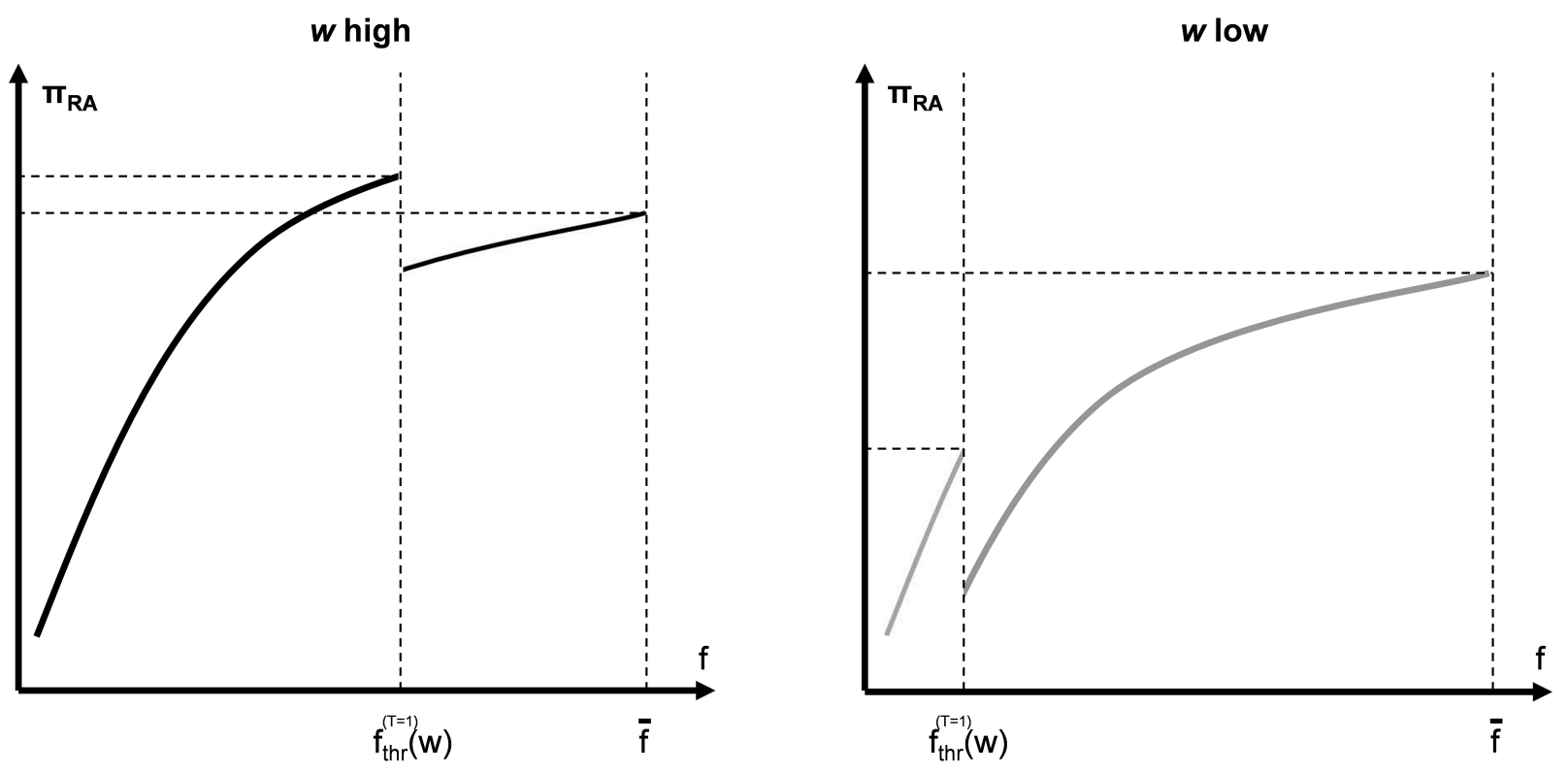

Figure 7: Payoff to benevolent rater: Left (right) shows the graph of the rater's payoff provided that it rates truthfully $(T=1)$ if the regulatory risk-weight $w$ is high (low).

expensive $A$-rating to the risky issuer:

$$
x^{*}(w, T=1, f)=\left\{\begin{array}{cl}
0, & \text { if } f \leq f_{t h r}^{(T=1)}(w) \\
\bar{x}(w, S), & \text { if } f>f_{t h r}^{(T=1)}(w)
\end{array}\right.
$$

Figure 7 illustrates that threshold $f_{t h r}^{(T=1)}(w)$ is an increasing function of the regulatory risk-weight $w$. In the left-hand graph of Figure $7 w$ is large as is $f_{t h r}^{(T=1)}(w)$ whereas the threshold is close to zero in the right-hand graph where $w$ is set at a low level. Strict regulation (high $w$ ) forces the bank to invest most of its capital into the risk-free issuer. It limits the bank's ability to avoid financing high fees for the expensive $A$-rating and allows the rater to charge higher fees without inducing excessive risk-taking.

As the rater's payoff in Figure 7 strictly increases in $f$ up to $f_{t h r}^{(T=1)}(w)$, clearly the rater will never charge less than $f_{t h r}^{(T=1)}(w)$. The rater might even find it optimal to charge a high fee that exceeds $f_{t h r}^{(T=1)}(w)$ if $w$ and hence $f_{t h r}^{(T=1)}(w)$ are very low. In the right-hand graph of Figure 7, the rater would have to charge an unsatisfactorily low fee to prevent the bank from increasing $x$ from 0 to $\bar{x}(w, S)$. For very low $w$, the rater instead chooses the highest fee $\bar{f}$ that its market power allows it to charge accepting that the bank will invest as little as possible in the $A$-rated issuer. 
When the regulator maximizes welfare (expected net return to overall investment) over its risk-weight $w$ at the first stage of the sequential game depicted in Figure 3, it rationally predicts how rater and bank will optimally choose $f^{*}$ and $x^{*}$ as functions of $w$ :

$$
\begin{aligned}
\max _{w} W\left(f^{*}(w), D^{*}=S, x^{*}(w)\right)= & (E+S) \cdot\left[\left(1-x^{*}(w)\right) \cdot\left(1-f^{*}(w)\right) \cdot\left(R_{f}-1\right)+\right. \\
& \left.x^{*}(w) \cdot(p \cdot R-1)\right]
\end{aligned}
$$

As the bottom plot of Figure 5 shows, welfare is positive and increasing in $D$ for low and for large leverage because the bank optimally allocates all capital to the issuer with the positive NPV project. ${ }^{29}$ To maximize welfare, the regulator chooses $w$ sufficiently large so that optimal bank leverage $S$ exceeds $D_{t h r}^{I I I}\left(w, f^{*}(w)\right)$. It takes into consideration that the rater will choose a rating fee that is so high $\left(f^{*}>f_{t h r}^{(T=1)}(w)\right)$ that the bank will take excessive risk $\left(x^{*}=\bar{x}\right)$ if it sets its risk-weight $w$ at too low a level. If $w_{t h r}^{(T=1)}$ denotes the threshold risk-weight above which the regulator prevents excessively high rating fees and excessive risk-taking, then the regulator chooses $w^{*} \geq w_{t h r}^{(T=1)}$.

Furthermore, threshold $f_{t h r}^{(T=1)}(w)$ increases in $w$. If the regulator sets a risk-weight that is larger than is necessary to insure $f^{*}(w)=f_{t h r}^{(T=1)}(w)$, then more capital would be paid to the rater in the form of fees being unavailable for investment in the positive NPV project. Hence, the regulator will choose precisely $w^{*}=w_{t h r}^{(T=1)}$.

Proposition 2. In the benchmark case with a benevolent rater that produces honest ratings, there exists a unique equilibrium under $R C C R$ in which

1. the regulator chooses risk-weight $w^{*}=w_{\text {thr }}^{(T=1)}$,

2. the rater chooses rating fee $f^{*}=f_{\text {thr }}^{(T=1)}\left(w^{*}\right)$,

3. the bank collects all supplied deposits $D^{*}=S$ and allocates all its capital to the risk-free $A$-rated issuer $\left(x^{*}=0\right)$,

4. welfare is larger than in the unregulated case and positive: ${ }^{30}$

$$
W\left(f_{t h r}^{(T=1)}\left(w^{*}\right), S, 0\right)=(E+S) \cdot\left(1-f_{t h r}^{(t=1)}\left(w^{*}\right)\right) \cdot\left(R_{f}-1\right) .
$$

${ }^{29}$ However, between $D_{t h r}^{I I}$ and $D_{t h r}^{I I I}$ welfare is smaller than for any $D \notin\left(D_{t h r}^{I I}, D_{t h r}^{I I I}\right)$. Up to $D=E \cdot \frac{1-w}{w}$ it decreases in $D$ as $\bar{x}(w, D)$ is 1 and regulation does not restrict the bank's position in the $B$-rated risky investment. Regulation restricts the risky position however for $D>E \cdot \frac{1-w}{w}$ where $\bar{x}(w, D)$ is smaller than 1 and welfare increases in $D$.

${ }^{30}$ For $w<\frac{E}{E+S}$ the bank is not regulated (see Equation (8)) and only finances the negative NPV investment. 
Proof: See Appendix.

\subsection{Opportunistic Rater}

I analyze a sequential game in which an opportunistic rater attributes its ratings in a way that maximizes its payoff. If the rater sets $T=1$, it attributes truthful ratings. But for $T=0$, the rater gives the $A$-rating to the risk-free as well as to the risky issuer. Otherwise, the game sequence is the same as in Section 5.1 (see Figure 3).

The rater sets $T=0$ if and only if the benefits of ratings inflation exceed its costs and $T=0$ maximizes the raters expected payoff:

$$
\mathbb{E}\left[\pi_{R A}\left(w, T=0, f^{*}(T=0)\right)\right]>\mathbb{E}\left[\pi_{R A}\left(w, T=1, f^{*}(T=1)\right)\right]
$$

If the rater inflates its ratings, it receives more fees than if it produces truthful ratings because a risky issuer is able to pay more for publishing an $A$-rating than a risk-free issuer. The reason is that the risky issuer receives a discount for providing the bank with a risky security that carries an (inflated) $A$-rating. The bank is willing to lend to the risky issuer on better terms because the higher investment risk increases the value of its shareholders' convex equity claim. At the same time the bank need not worry about regulatory punishment because risk-free as well as risky bank assets both carry $A$-ratings. The bank's position in an investment without an $A$-rating is zero for any allocation $x$ and bank equity always exceeds risk-weighted assets. For $T=0$ RCCR breaks down, the bank optimally levers up as much as possible $\left(D^{*}=S\right)$ and maximizes investment risk $\left(x^{*}=1\right)$.

In Assumption 5 I require the fees that the rater receives under $T=0$ to be constrained by Inequality (11). The fee conditional on $T=0$ must be low enough that the bank's expected payoff for $T=0$ is as least as high as for $T=1 .{ }^{31}$ As the bank's expected payoff for $T=1$ decreases in $w$, it follows that the optimal fee conditional on $T=0$ increases in $w$.

Lemma 3. Conditional on $T=0$ and $w$ and subject to (11)

1. the bank collects all supplied deposits $S$ and allocates all its capital to the $\boldsymbol{A}$-rated risky issuer with the negative NPV-project $\left(x^{*}=1\right)$,

2. the rater chooses fee $f_{t h r, i}^{(T=0)}(w)$ if risk-weight $w \geq w_{t h r}^{(T=1)}$. Otherwise the rater chooses fee $f_{\text {thr }, i i}^{(T=0)}(w)<f_{\text {thr, } i}^{(T=0)}(w)$.

\footnotetext{
${ }^{31}$ Without Assumption 5 ratings inflation would be more profitable as the rater would charge even higher fees skimming off the entire expected return to investment.
} 
Proof: See Appendix.

Apart from higher fees the decision to inflate ratings also generates costs for the rater. If an $A$-rated issuer defaults, the regulator discovers that it was misled as only the risky issuer can default. As welfare is negative for $x=1$, the regulator abandons RCCR in favor of RICR and the rater loses future RCCR-contingent revenues $P$. Therefore, the rater will inflate its ratings only if the incremental fee revenues of ratings inflation exceed the expected loss of future revenues:

$$
(E+S) \cdot f^{*}(w, T=0)-(E+S) \cdot\left(1-x^{*}(w, T=1)\right) \cdot f^{*}(w, T=1)>(1-p) \cdot P
$$

Let $P_{t h r}(w)$ denote the value of $P$ for which the above inequality holds as an equality.

Proposition 3. The rater's decision whether to attribute the A-rating to both or only to the risk-free issuer under $R C C R$ will depend on the size $P$ of future business that the rater will lose if it is caught inflating its ratings:

(a) If $P \geq P_{t h r}(w)$, the rater produces truthful ratings $\left(T^{*}=1\right)$.

(b) If $P<P_{t h r}(w)$,

1. the rater inflates its ratings $\left(T^{*}=0\right)$ and sets its fee according to Lemma 3,

2. the bank collects $D^{*}=S$ and allocates all capital to the risky issuer $\left(x^{*}=1\right)$.

3. welfare is negative:

$$
W\left(f^{*}(w, T=0), S, x^{*}=1\right)=(E+S) \cdot\left(1-f^{*}(w, T=0)\right) \cdot(p \cdot R-1)<0 .
$$

Proof: Omitted.

For $P \geq P_{t h r}(w)$, the RCCR-contingent revenues $P$ are sufficiently large that the threat to switch from RCCR to RICR disciplines the rater and RCCR successfully prevents the bank from excessive risk-taking. Importantly, the regulator cannot use a similar threat to discipline the bank directly. When the default of the bank reveals excessive risk-taking in the past, there is no bank equity left from which the regulator could levy a penalty. As the default puts the bank out of business, also a threat to tax future bank profits would not discipline the bank.

For $P<P_{t h r}(w)$, future RCCR-contingent income is so low that the regulatory threat to introduce RICR does not discipline the rater. Rater, bank and risky issuer collude at the 
expense of the state which insures deposits and bears the welfare cost. ${ }^{32}$ Importantly, the rater inflates ratings despite its free access to credit risk information. This contrasts with Harris et al. (2013) who rely on costly information acquisition to generate ratings inflation.

The main idea behind this result can be understood as follows. Due to the convex form of its equity claim, the investor in this model (the bank) has a larger appetite for investment risk than is welfare-optimal, whereas the investor in Harris et al. (2013) dislikes investment risk and prefers investment in the welfare-optimal security. The bank in this model welcomes ratings inflation as a way to arbitrage regulation whereas the investor in Harris et al. (2013) charges a premium for the risk of buying a risky security with an inflated $A$-rating. ${ }^{33}$ The two oppositional risk preferences of investors in this paper and in Harris et al. (2013) impact the maximization problem of the rater in fundamentally different ways. In Harris et al. (2013), the premium that investors charge for the risk of an inflated rating lowers the surplus that raters can extract from issuers and the rater loses money on every bad security that is rated $A$. Hence, ratings inflation only occurs if information acquisition is sufficiently expensive. In this paper, the rater makes money on every high-risk security that is rated $A$ because the rater participates in the bank's incremental profits of risk-taking. Hence, ratings inflation also occurs if the rater and the investor (the bank) have free access to information.

\section{Optimal Regulation}

\subsection{Optimal Choice Between RCCR and RICR}

Will the regulator limit bank leverage (RICR) or optimally calibrate capital requirements to bank asset risk based on credit ratings (RCCR)? The regulator optimally chooses RCCR if and only if RCCR maximizes welfare:

$$
W\left(P, R C C R, w^{*}\right)>W\left(R I C R, \bar{D}^{*}\right)
$$

Welfare under RICR is clearly positive if the regulator optimally chooses $\bar{D}^{*}=D_{t h r}^{I}$ (see Proposition 1). Whether welfare under RCCR is negative or positive on the other hand depends on the risk-weight $w$ and on the size of future rating income $P$. $P$ must be high

\footnotetext{
${ }^{32}$ For $P=0$ collusion between rater and bank is the only equilibrium under RCCR (see Appendix).

${ }^{33}$ This premium ensures that the investor in Harris et al. (2013) does on average not lose out when buying a security with a potentially inflated rating. But ex-post, once the purchase of an $A$-rated security has been effectuated, the investor is strictly better off if the purchased asset is of the low-risk type and carries an unbiased rating.
} 
enough that, conditional on the chosen risk-weight, the rater optimally produces honest ratings and helps the regulator identify issuer types. Furthermore, the chosen risk-weight must be high enough to prevent excessive risk-taking.

Lemma 4. Welfare $W(P, R C C R, w)$ under $R C C R$ is

(a) positive if and only if $P \geq P_{t h r}(w)$ and $w \geq w_{t h r}^{(T=1)}$,

(b) maximized for $w^{*}=w_{t h r}^{(T=1)}$ provided that $P \geq P_{t h r}\left(w_{t h r}^{(T=1)}\right)$.

Proof: See Appendix.

Provided that $P \geq P_{t h r}\left(w_{t h r}^{(T=1)}\right)$ and $w=w_{t h r}^{(T=1)}$, the rater risks losing enough future income when it is caught lying so that it optimally rates truthfully. In that case, RCCR can provide a welfare gain relative to RICR because the bank is allowed to collect a larger number of deposits, which it can pass on to the risk-free issuer. ${ }^{34}$ RICR on the other hand limits credit supply to the real economy and total investment in the positive NPV-project. Provided that $P \geq P_{t h r}\left(w_{t h r}^{(T=1)}\right)$ and $w=w_{t h r}^{(T=1)}$, the welfare gain of RCCR relative to RICR is:

$$
\begin{aligned}
W\left(P>P_{t h r}\left(w_{t h r}^{(T=1)}\right), w_{t h r}^{(T=1)}\right)-W\left(D_{t h r}^{I}\right)= & (E+S) \cdot\left(1-f^{*}\right) \cdot\left(R_{f}-1\right)- \\
& \left(E+D_{t h r}^{I}\right) \cdot\left(R_{f}-1\right) .
\end{aligned}
$$

This welfare gain is positive provided that $S$ is sufficiently large. ${ }^{35}$ It follows that a rational regulator that anticipates when bank, rater and risky issuer collude will choose RCCR if and only if $P \geq P_{t h r}\left(w_{t h r}^{(T=1)}\right)$.

Proposition 4. If the regulator can choose between $R I C R$ and $R C C R$ with an opportunistic rater, there exists a unique equilibrium in which

\footnotetext{
${ }^{34}$ This result relies on the assumption that the bank cannot easily substitute debt by equity financing. Myers (1977), Miller (1977) and Myers \& Majluf (1984) provide classical arguments from the corporate finance literature why banks can be reluctant to raise new equity capital. Diamond \& Dybvig (1983) and Diamond (1984) demonstrate the advantages of highly liquid and informationally insensitive debt instruments for financial intermediaries. Adrian \& Shin (2012) find empirical evidence that equity is indeed the privately more expensive form of bank financing.

${ }^{35}$ This is the case for $S \geq E \cdot \frac{R_{f}-p \cdot R_{f}}{p \cdot(R-1)-\left(R_{f}-1\right)}$. Otherwise, the welfare gain of RCCR is still positive provided that the rater's market power $\bar{f}$ is sufficiently low and little capital is paid to the rater in the form of fees instead of being invested in the real economy. In the extreme case of $\bar{f}=0$ in which the rater cannot charge any fees the efficiency gain is $\left(S-D_{t h r}^{I}\right) \cdot\left(R_{f}-1\right)$ (see Appendix E).
} 
(a) If $P \geq P_{t h r}\left(w_{t h r}^{(T=1)}\right)$, the regulator chooses $R C C R .\left(w^{*}, f^{*}, D^{*}, x^{*}\right)$ are chosen according to Proposition 2.

(b) If $P<P_{t h r}\left(w_{t h r}^{(T=1)}\right)$, the regulator chooses $R I C R$. $\left(\bar{D}^{*}, D^{*}, x^{*}\right)$ are chosen according to Proposition 1.

Proof: Omitted.

\subsection{Unresponsive Regulation and Time-Varying Ratings Accu- racy}

According to Proposition 4, the regulator optimally chooses RCCR if the RCCR-contingent

revenues $P$ exceed threshold $P_{t h r}\left(w_{t h r}^{(T=1)}\right)$. Only then can the threat to switch from RICR to RCCR in the future discipline the rater to produce truthful ratings. In practice, major regulatory reforms like a change between regulatory regimes tend to take place only in intervals of several years. They are typically preceded by consultations between the financial industry and regulators and are negotiated multilaterally. The potentially long time needed to abandon RCCR in favor of RICR makes regulators unresponsive to changing incentives for moral hazard, which themselves covary with economic business cycles over time. Analyzing the comparative statics of the rater's trade-off between short-term benefits of ratings inflation and an expected loss of future RCCR-contingent revenues helps determine the sensitivity of incentives to fundamentals.

For initially fixed risk-weight $w$ threshold $P_{t h r}(w)$ decreases in the return $R_{f}$ of the investment with a positive NPV. When $R_{f}$ is small, bank incentives to substitute the safe for the risky security are relatively high. Similarly the incremental profit from excessive risktaking that is available to capture the rating agency increases, too. Hence, higher incentives for moral hazard in the banking industry translate into higher incentives for moral hazard in the rating industry. As $R_{f}$ falls, threshold $P_{t h r}(w)$ can increase until it exceeds $P$ and the rating agency optimally lies about credit risk.

If $R_{f}$ is interpreted as the profitability of traditional banking, this model predicts that incentives for ratings inflation increase as interest rates fall. According to Gorton (2009) and Hellmann et al. (2000), the abolition of entry barriers to banking has led competition in traditional banking to increase since the 1990s. Issuers of junk bonds have taken business from the asset side of bank balance sheets while money market funds have reduced the demand for bank deposits. Commercial banks copying the business model of investment banks reduced profitability in investment banking, too. Finally, an expansionary monetary 
policy after the burst of the dot.com bubble has reduced interest rates increasing incentives for risk-shifting and ratings inflation further.

A decreasing profitability of traditional bank business will only lead to risk-shifting if there exist alternative investments that offer banks more attractive yields. Indeed, the threshold $P_{t h r}$ increases in the risky return $R$. Interpreting $R$ as the return on innovative structured debt, my model predicts that incentives for ratings inflation increase as the supply of structured debt grows.

In summary, regulation appears unresponsive to changing incentives for ratings inflation, which themselves are highly sensitive to fundamentals and business cycles. This observation can explain why RCCR was implemented although it would break down later. ${ }^{36}$ If incentives for moral hazard were low at the time when RCCR was introduced, RCCR was indeed the optimal choice according to Proposition 4. However, as later interest rates fell and highyield innovative markets emerged, RCCR failed which probably motivated the subsequent introduction of a risk-independent leverage limit into Basel III and the suggested elimination of RCCR in the Dodd-Frank Act. This trend towards RICR is consistent with my model in which the regulator abandons RCCR in favor of RICR in case that rater and bank collude.

\subsection{Regulating Rating Agencies}

Abandoning RCCR in favor of RICR is a drastic way to reform bank regulation and could meet significant opposition from the industry. Here, I discuss whether more regulation of rating agencies can prevent moral hazard instead:

(a) In my model the rater has an incentive to inflate the quality of its ratings because it receives fees $f \geq 0$ from an issuer with an $A$-rating upon successful funding by the bank whereas a $B$-rated issuer does not publish its rating. Bolton et al. (2012) suggest obliging raters to disclose all ratings. The same authors point out, however, that informal discussions between issuers and raters could still take place and that issuers might only ask for risk analyses if raters signaled upfront that they would be accommodating.

(b) Pagano \& Volpin (2010) suggest the return to the investors-pay model in which the rating agency is not paid by the issuers but by the bank that buys the securities. ${ }^{37}$

\footnotetext{
${ }^{36}$ Hunt (2009) counted at least 44 SEC rules relying on credit ratings as of June 2008. Basel II was initially published in 2004.

${ }^{37}$ The investors-pay model was abandoned in favor of the current issuers-pay model in the early 1970s because of free riding among investors.
} 
The idea is that investors have a natural interest in truthful investment risk ratings. Unfortunately, I showed in Section 5.2 that a risk-loving bank welcomes ratings inflation as it allows to circumvent RCCR. Collusion between bank and rater could be prevented if the investors were forbidden to pay the rating agency individually and if the fees were paid from a tax on financial transactions, for example. However, a tax-financed rating agency might experience political pressure and, for example, inflate sovereign debt ratings. Also, tax-financing essentially transforms the private into a public rating agency that could lack expertise and motivation to rate thoroughly.

(c) A penalty that the regulator imposes on the rater works essentially like the regulatory threat of abandoning RCCR in favor of RICR when ratings inflation becomes evident. The regulator could simply withdraw the accreditation of the rater as a Nationally Recognized Statistical Rating Organization and accredit another rating agency instead. The Dodd-Frank Wall Street Reform and Consumer Protection Act signed in 2010 explicitly allows the SEC to discipline raters this way. ${ }^{38}$ Alternatively, the regulator could charge a monetary penalty to be levied from the rater's equity. European politicians make concrete plans about how to hold agencies liable for their ratings. ${ }^{39}$ Both suggestions can work in theory but a methodology able to prove ratings inflation for single raters on an individual basis runs the risk to be misspecified and to dissatisfy legal requirements.

\section{Robustness of Results}

\subsection{Uninformed Investors and Ratings Inflation}

The mechanisms leading to ratings inflation could be weakened by the existence of small investors outside regulation. Such presumably uninformed investors use ratings to better assess the risk-return properties of securities and could perhaps discipline opportunistic raters. ${ }^{40}$ However, the criticism of ratings inflation is mainly relevant for structured complex securities - products rarely sold to retail investors.

Furthermore, the influence of retail investors on ratings accuracy is not unambiguously positive. If retail investors do not understand incentives for ratings inflation and take ratings

\footnotetext{
${ }^{38}$ Stolper (2009) shows theoretically that it is possible to accredit rating agencies for regulatory purposes in such a way that they do not engage in ratings inflation.

${ }^{39}$ See Footnote 5.

${ }^{40}$ I thank Rajna Gibson Brandon and Stefan Hirth for pointing this out.
} 
at face value, they fit into the description of Bolton et al. (2012) as a trusting investor clientele and can aggravate ratings inflation rather than discipline raters.

Finally, this abstract model focuses on the channels through which the regulatory function of ratings negatively influences ratings quality and endangers the success of bank regulation. That uninformed investors might (or might not) increase incentives for honest ratings production changes nothing about the finding that RCCR decreases these very same incentives. If RCCR was abandoned and the regulatory function of ratings was hence eliminated, this would not stop ratings to benefit uninformed investors. In fact, my model suggests that ratings would become more informative and more beneficial to uninformed investors.

\subsection{Internal Ratings-Based Approach}

So far this paper has not accounted for the Internal Ratings-Based (IRB) approach of Basel II under which banks may rely on their own internal risk estimates. The largest banks mostly follow this IRB whereas small and medium-sized banks mainly adopt the Standard Approach modeled here as RCCR. However, the presented framework is also relevant for the IRB in two ways. First, if the bank-internal risk estimates rely to some extent on external ratings, the latter continue to offer a regulatory relief to banks. Secondly, if a bank has governance problems and its business divisions succeed to influence the risk management and audit department, then regulation based on bank-internal ratings compares to collusion between rater and bank in its most extreme form. In a sense, the previously external rater has simply been incorporated into the bank being all the more susceptible to capture now. ${ }^{41}$

\section{Conclusion}

The success of rating-contingent regulation (RCCR) at constraining risky bank investment depends on the benevolence of rating agencies to rate bank assets truthfully. When the incentives of private opportunistic rating agencies to produce truthful ratings are not aligned with the objectives of regulators, RCCR can break down. Importantly, the implementation of RCCR itself alters the incentives of rating agencies for honest information revelation in the sense of the Lucas-critique. Under RCCR investment-grade ratings relax the regulatory constraints of institutional investors like banks, which will consequently increase their willingness-to-pay for assets with good ratings. Issuers of bank assets will use part of the

\footnotetext{
${ }^{41}$ For a detailed discussion of governance problems in banking see Hellwig (2010).
} 
regulatory benefit offered by good ratings to capture the rating agencies. Hence, RCCR augments incentives for deliberate ratings inflation.

If investing banks, issuers of risky bank assets and rating agencies collude, RCCR fails to prevent banks from risk-shifting. In this situation the abolition of RCCR in favor of rating-independent capital requirements (RICR) improves welfare. RICR eliminates riskshifting incentives of banks as the leverage limit obliges bank shareholders to gamble with their own capital. Therefore, RICR is much less susceptible to gaming as compared to RCCR which only attempts to control these incentives by discriminating bank assets with low credit ratings. The caveat of RICR is that it potentially limits credit supply to projects with positive NPV. Therefore, if regulation can discipline rating agencies to be honest, then RCCR would yield higher welfare than RICR.

The threat to replace RCCR by RICR in the future if ratings inflation becomes public knowledge can restore truthful information revelation. However, this threat will only discipline rating agencies if they fear to lose a sufficiently large amount of future revenues in case that RCCR is abandoned. As the trade-off between short-term profits and long-term costs of ratings inflation varies over time together with economic fundamentals, regulators are unlikely to be responsive enough to adjust RCCR each time they predict incentives for ratings inflation and risk-shifting to increase. RCCR would at times fail to prevent collusion between issuers, banks and raters with fatal economic consequences. Abandoning RCCR in favor of RICR would increase the stability of the financial system. 


\section{Appendix}

\section{A Proof to Proposition 2}

I solve the game depicted in Figure 3 by backward induction using $f \leq \bar{f}$ (Assumption 5 ).

\section{Stage 4:}

The bank maximizes its expected payoff to shareholders over the allocation $x$ for given $D$ and subject to the regulatory constraint (9):

$$
\max _{x} \mathbb{E}\left[\pi_{B}(f, D, x)\right] \text { s.t. } x \leq \bar{x}(w, D)
$$

Regulation restricts the bank to lend at most $\bar{x}(w, D)$ to the risky issuer without the $A$ rating. From Lemma 1 it follows that $x^{*}(w, f, D) \in\{0, \bar{x}(w, D)\}$. To determine the optimal choice of $x^{*}$ conditional on $D$ I compare the expected shareholder payoffs for $x=0$ and $x=\bar{x}(w, D)$ :

(a) The expected shareholder payoff for $x=0$ is: $\mathbb{E}\left[\pi_{B}(w, f, D, 0)\right]=(E+D) \cdot(1-f) \cdot R_{f}-D$

(b) The expected shareholder payoff for $x=\bar{x}(w, D)$ is computed for different levels of $D$ :

- $D \leq E \cdot \frac{1-w}{w} \Leftrightarrow \bar{x}(w, D)=1$ :

$$
\mathbb{E}\left[\pi_{B}(w, f, D, \bar{x}(w, D))\right]=p \cdot[(E+D) \cdot R-D]
$$

- $E \cdot \frac{1-w}{w}<D \leq E \cdot \frac{(1-f) \cdot R_{f}}{(1-f) \cdot R_{f}-1} \cdot \frac{1-w}{w} \Leftrightarrow 1-\frac{D}{(E+D) \cdot(1-f) \cdot R_{f}} \leq \bar{x}(w, D)<1$ :

$$
\begin{aligned}
\mathbb{E}\left[\pi_{B}(w, f, D, \bar{x}(w, D))\right] & =p \cdot\left[D \cdot\left[(1-f) \cdot R_{f}-1\right]\right. \\
& \left.+E \cdot\left((1-f) \cdot R_{f}+\frac{1}{w} \cdot\left(R-(1-f) \cdot R_{f}\right)\right)\right]
\end{aligned}
$$

$$
\text { - } \begin{aligned}
& D>E \cdot \frac{(1-f) \cdot R_{f}}{(1-f) \cdot R_{f}-1} \cdot \frac{1-w}{w} \Leftrightarrow 1-\frac{D}{E+D} \cdot \frac{1}{(1-f) \cdot R_{f}}>\bar{x}(w, D): \\
& \mathbb{E}\left[\pi_{B}(w, f, D, \bar{x}(w, D))\right]=D \cdot\left[(1-f) \cdot R_{f}-1\right]+E \cdot(1-f) \cdot R_{f} \cdot\left(1-\frac{1}{w}\right)+E \cdot p \cdot R \cdot \frac{1}{w}
\end{aligned}
$$

A comparison of the expected shareholder payoff for $x=0$ and for $x=\bar{x}(w, D)$ shows 
that their graphs intercept at the two thresholds

$$
\begin{aligned}
& D_{t h r}^{I I}(f):=E \cdot \frac{(1-f) \cdot R_{f}-p \cdot R}{p \cdot(R-1)-\left[(1-f) \cdot R_{f}-1\right]} \\
& D_{t h r}^{I I I}(w, f):=E \cdot \frac{p \cdot R-p \cdot(1-w) \cdot(1-f) \cdot R_{f}-w \cdot(1-f) \cdot R_{f}}{(1-p) \cdot\left[(1-f) \cdot R_{f}-1\right] \cdot w}
\end{aligned}
$$

provided that $w$ is not too large. Note that the lower threshold $D_{t h r}^{I I}(f)$ decreases in $f$ whereas the upper threshold $D_{t h r}^{I I I}(w, f)$ increases in $f$ but decreases in $w$. Lemma 5 follows:

Lemma 5. Under RCCR with a benevolent honest rater, the bank chooses the portfolio allocation $^{42}$

$$
x^{*}(w, f, D)=\left\{\begin{array}{cl}
0, & \text { if } D \notin\left(D_{t h r}^{I I}(f), D_{t h r}^{I I I}(w, f)\right) \\
\bar{x}(w, D), & \text { if } D \in\left(D_{t h r}^{I I}(f), D_{t h r}^{I I I}(w, f)\right)
\end{array} .\right.
$$

\section{Stage 3:}

The bank maximizes the expected payoff to its shareholders over $D$ :

$$
\max _{D} \mathbb{E}\left[\pi_{B}\left(f, D, x^{*}(w, f, D)\right)\right]
$$

where $x^{*}$ is determined as in Lemma 5. The expected payoffs for $x=0$ as well as for $x=\bar{x}$ are both increasing in $D$. The bank optimally meets the supply of deposits $\left(D^{*}=S\right)$. By Inequality (2), $S$ exceeds the lower threshold $D_{t h r}^{I I}(f)$. It follows from Lemma 5 that the bank chooses the welfare-optimal portfolio $x^{*}=0$ if and only if $S$ also exceeds the upper threshold $D_{t h r}^{I I I}(w, f)$. Whether $S$ exceeds the upper threshold $D_{t h r}^{I I I}(w, f)$ depends on the rating fee $f$. Equating $S$ and $D_{t h r}^{I I I}(w, f)$ and solving for $f$ gives the threshold fee $f_{\text {thr }}^{(T=1)}(w)$ above which excessive risk-taking prevails.

Lemma 6. Under RCCR with a benevolent honest rater, the bank finds it optimal to meet the supply of deposits $D^{*}=S$. The bank's optimal portfolio choice depends on $f$ in the following way:

$$
\begin{gathered}
x^{*}(w, f)=\left\{\begin{array}{cl}
0, & \text { if } f \leq f_{\text {thr }}^{(T=1)}(w) \\
\bar{x}(w, S), & \text { if } f>f_{\text {thr }}^{(T=1)}(w)
\end{array}\right. \\
\text { where } f_{\text {thr }}^{(T=1)}(w):=\frac{S \cdot w \cdot\left(R_{f}-1\right) \cdot(1-p)+E \cdot\left[R_{f} \cdot(w+p-w \cdot p)-p \cdot R\right]}{R_{f} \cdot[S \cdot w \cdot(1-p)+E \cdot(p+w-p \cdot w)]}
\end{gathered}
$$

\footnotetext{
${ }^{42}$ For very high $w$ the expected shareholder payoff for $x=0$ can be higher than for $x=\bar{x}(w, D)$ for all $D$. In that case the two intercepts $D_{t h r}^{I I}(f)$ and $D_{t h r}^{I I I}(w, f)$ do not exist and the bank always chooses $x^{*}=0$.
} 
According to Lemma 6, excessive risk-taking occurs when the rater charges high fees $f>f_{t h r}^{(T=1)}(w)$. A high fee $f$ lowers the NPV of the risk-free investment from the bank's point of view and allocating capital to the risky project type becomes relatively more attractive. $f_{t h r}^{(T=1)}(w)$ increases in $w$. The higher the regulatory risk-weight, the higher the fee that the rater can charge without inducing excessive risk-taking.

\section{Stage 2:}

The rater maximizes its payoff over fee $f$ :

$$
\max _{f} \pi_{R A}(w, f)=(E+S) \cdot\left(1-x^{*}(w, f)\right) \cdot f
$$

The rater's payoff is strictly increasing in $f$ on the intervals $\left[0, f_{t h r}^{(T=1)}(w)\right)$ and on the interval $\left(f_{t h r}^{(T=1)}(w), \bar{f}\right)$ (see Figure 7 ). At $f=f_{\text {thr }}^{(T=1)}(w)$ the rater's payoff drops because $\left(1-x^{*}(w, f)\right)$ drops from 1 to $(1-\bar{x}(w, S))$. At $f=\bar{f}$ the rater's payoff drops to zero as $\bar{f}$ is assumed to be the highest fee that the rater can charge (Assumption 5). It follows that the optimal fee must be in the set $\left\{\bar{f}, f_{t h r}^{(T=1)}(w)\right\}$ and the rater's problem reduces to

$$
\max _{f \in\left\{\bar{f}, f_{t h r}^{(T=1)}(w)\right\}} \pi_{R A}(w, f)=\left\{\begin{array}{cl}
(E+S) \cdot(1-\bar{x}(w, S)) \cdot \bar{f}, & \text { if } f>f_{\text {thr }}^{(T=1)}(w) \\
(E+S) \cdot f_{t h r}^{(T=1)}(w), & \text { if } f \leq f_{\text {thr }}^{(T=1)}(w)
\end{array} .\right.
$$

Notice that the threshold fee $f_{t h r}^{(T=1)}(w)$ exceeds $\bar{f}$ for large risk-weights that exceed $E$. $\frac{p \cdot\left[R-R_{f} \cdot(1-\bar{f})\right]}{(E+S) \cdot(1-p) \cdot R_{f} \cdot(1-\bar{f})-S \cdot(1-p)}$. In that case the rater optimally sets $f^{*}(w)=\bar{f}$ and its payoff is $(E+S) \cdot \bar{f}$. For low risk-weights $w \leq E \cdot \frac{p \cdot\left[R-R_{f} \cdot(1-\bar{f})\right]}{(E+S) \cdot(1-p) \cdot R_{f} \cdot(1-\bar{f})-S \cdot(1-p)}$, on the other hand, $f_{\text {thr }}^{(T=1)}(w)$ is smaller than $\bar{f}$. In this latter case I need to compute the rater's payoffs for both choices of $f \in\left\{\bar{f}, f_{t h r}^{(T=1)}(w)\right\}$. The rater then chooses the fee for which its payoff is higher.

(a) For fee $f=\bar{f}>f_{\text {thr }}^{(T=1)}(w)$ the rater's payoff is

$$
\pi_{R A}(w, f)=\frac{(E+S) \cdot w-E}{w} \cdot \bar{f}
$$

which increases in the rater's market power $\bar{f}$ provided that Inequality (8) is satisfied (that the bank is regulated). 
(b) For fee $f=f_{t h r}^{(T=1)}(w) \leq \bar{f}$ the rater's payoff is

$$
\pi_{R A}(w, f)=(E+S) \cdot f_{t h r}^{(T=1)}(w)
$$

A comparison of the two payoffs for $f=\bar{f}>f_{t h r}^{(T=1)}(w)$ and $f=f_{t h r}^{(T=1)}(w) \leq \bar{f}$ gives the threshold $w_{t h r}^{(T=1)}$ above which the rater best chooses $f^{*}(w)=f_{t h r}^{(T=1)}(w) \leq \bar{f}$ and otherwise $f^{*}(w)=\bar{f}$.

$$
\begin{aligned}
\frac{(E+S) \cdot w-E}{w} \cdot \bar{f} & <(E+S) \cdot f_{t h r}^{(T=1)}(w) \\
\Leftrightarrow w^{2}-Y(\bar{f}) \cdot w+Z(\bar{f}) & >0
\end{aligned}
$$

$$
\begin{aligned}
& \text { where } \quad Y(\bar{f}):=E \cdot \frac{p \cdot\left(R-R_{f}\right)+\bar{f} \cdot R_{f} \cdot(2 p-1)}{(1-p) \cdot\left[E \cdot(1-\bar{f}) \cdot R_{f}+S \cdot\left((1-f) \cdot R_{f}-1\right)\right]} \\
& Z(\bar{f}):=\frac{E}{E+S} \cdot \frac{p}{1-p} \cdot \frac{E \cdot R_{f} \cdot \bar{f}}{R_{f} \cdot(1-\bar{f}) \cdot(E+S)-S}
\end{aligned}
$$

The nulls of the quadratic inequality are $\frac{1}{2} \cdot Y(\bar{f})-\frac{1}{2} \sqrt{Y(\bar{f})^{2}-4 \cdot Z(\bar{f})}$ and $\frac{1}{2} \cdot Y(\bar{f})+$ $\frac{1}{2} \sqrt{Y(\bar{f})^{2}-4 \cdot Z(\bar{f})}$ of which only the latter (bigger) satisfies Inequality (8). The quadratic inequality is hence satisfied for $w \in\left[\frac{1}{2} \cdot Y(\bar{f})+\frac{1}{2} \sqrt{Y(\bar{f})^{2}-4 \cdot Z(\bar{f})}, \infty\right)$. Denote the lower bound of this interval as $w_{t h r}^{(T=1)}$ :

$$
w_{t h r}^{(T=1)}(\bar{f}):=\frac{1}{2} \cdot Y(\bar{f})+\frac{1}{2} \sqrt{Y(\bar{f})^{2}-4 \cdot Z(\bar{f})}
$$

Note that the threshold $\left.w_{t h r}^{(T=1)}(\bar{f})\right)$ is an increasing function in the rater's bargaining power. The higher $\bar{f}$ the higher must be the regulatory risk-weight to ensure that the rater still charges sufficiently low fees $f^{*}(w)=\min \left\{f_{t h r}^{(T=1)}(w), \bar{f}\right\}$ and that the bank still chooses the welfare-optimal portfolio $x^{*}(w, f)=0$. Furthermore, note that this threshold $w_{\text {thr }}^{(T=1)}(\bar{f})$ is smaller than $E \cdot \frac{p \cdot\left[R-R_{f} \cdot(1-\bar{f})\right]}{(E+S) \cdot(1-p) \cdot R_{f} \cdot(1-\bar{f})-S \cdot(1-p)}$ by construction so that $f_{t h r}^{(T=1)}\left(w_{t h r}^{(T=1)}(\bar{f})\right)$ is smaller than $\bar{f}$.

Lemma 7. Under RCCR with a benevolent honest rater, the rater finds it optimal to choose 
its rating fee $f$ in the following way:

$$
f^{*}(w)=\left\{\begin{array}{cl}
\bar{f}, & \text { if } w<w_{t h r}^{(T=1)}(\bar{f}) \\
\min \left\{f_{t h r}^{(T=1)}(w), \bar{f}\right\}, & \text { if } w \geq w_{t h r}^{(T=1)}(\bar{f})
\end{array}\right.
$$

\section{Stage 1:}

The regulator maximizes welfare defined as total expected surplus:

$$
\begin{aligned}
\max _{w} W\left(f^{*}(w), S, x^{*}(f(w))\right)= & (E+S) \cdot\left[\left(1-x^{*}(f(w))\right) \cdot\left(1-f^{*}(w)\right) \cdot\left(R_{f}-1\right)+\right. \\
& \left.x^{*}(f(w)) \cdot(p \cdot R-1)\right]
\end{aligned}
$$

Welfare is largest for $S>D_{t h r}^{I I I}(w, f)$. The optimal risk-weight is hence necessarily in the interval $\left[w_{t h r}^{(T=1)}(\bar{f}), \infty\right)$. As $f^{*}(w)=\min \left\{f_{t h r}^{(T=1)}(w), \bar{f}\right\}$ for $w \geq w_{t h r}^{(T=1)}(\bar{f}), f^{*}(w)$ is increasing in $w$. The risk-free issuer uses a larger part of its bank loan to finance rating fees as $w$ increases. Consequently, the amount of capital invested in the project with positive NPV decreases in $w$ on the interval $\left[w_{t h r}^{(T=1)}(\bar{f}), \infty\right)$. Hence, the bank optimally chooses $w=w_{t h r}^{(T=1)}(\bar{f})$. I can summarize the optimal strategies of regulator, rater and bank in the following equilibrium:

Equilibrium. Under $R C C R$ the regulator, a benevolent rating agency and the bank play the following optimal strategies in equilibrium:

1. The regulator sets $w^{*}=w_{t h r}^{(T=1)}(\bar{f})$.

2. The rater sets its fee according to Lemma 7.

3. The bank sets $D^{*}$ and $x^{*}$ according to Lemma 6 .

This completes the proof.

\section{B Proof to Lemma 3}

To simplify the exposition of the solution, I make the initial guess that the bank optimally chooses $x^{*}=1$ and $D^{*}=S$ conditional on $T=0$. I will verify ex-post that this guess is indeed true. I must distinguish two cases (i) $w \geq w_{t h r}^{(T=1)}$ and (ii) $w<w_{t h r}^{(T=1)}$ to derive the rating fee that the rater optimally charges in each case: 
(a) $w \geq w_{t h r}^{(T=1)}$

The rater optimally charges $f^{*}(w, T=1)=\min \left\{f_{t h r}^{(T=1)}(w), \bar{f}\right\}$ and the bank optimally sets $x^{*}(w, T, f)=0$ and $D^{*}=S$ conditional on $T=1$ according to Lemmas 7 and 6. The bank's participation constraint (11) becomes

$$
\begin{gathered}
\mathbb{E}\left[\pi_{B}(T=0, f, S, x=1)\right] \geq \mathbb{E}\left[\pi_{B}\left(T=1, f^{*}(w, T), S, x=0\right)\right] \\
\Leftrightarrow p \cdot[(E+S) \cdot(1-f) \cdot R-S] \geq(E+S) \cdot\left(1-f^{*}(w, T=1)\right) \cdot R_{f}-S .
\end{gathered}
$$

This inequality holds as an equality for a threshold fee

$$
f_{t h r, i}^{(T=0)}(w):=\frac{(E+S) \cdot\left[p \cdot R-\left(1-f^{*}(T=1)\right) \cdot R_{f}\right]+S \cdot(1-p)}{p \cdot(E+S) \cdot R} .
$$

If the rater sets a fee above this threshold, then the bank will not agree on ratings inflation but will force the rater to rate truthfully $(T=1)$. As the rater's payoff conditional on $T=0$ and subject to the bank's participation constraint $(11)$ is given by $(E+S) \cdot f$, it is strictly increasing up to $f_{t h r, i}^{(T=0)}(w)$. Subject to the bank's participation constraint and conditional on $T=0$, the rater hence optimally sets $f^{*}(T=0)=f_{t h r, i}^{(T=0)}(w)$.

(b) $w<w_{t h r}^{(T=1)}$

Conditional on $T=1$, the rater optimally charges a fee $f^{*}(w, T=1)=\bar{f}$ and the bank optimally sets $x^{*}=\bar{x}(w, S)$ and $D^{*}=S$ according to Lemmas 7 and 6 . The bank's participation constraint (11) becomes

$$
\begin{aligned}
& \mathbb{E}\left[\pi_{B}(T=0, f, S, x=1)\right] \quad \geq \mathbb{E}\left[\pi_{B}(T=1, \bar{f}, S, \bar{x}(w, S))\right] \\
\Leftrightarrow p \cdot[(E+S) \cdot(1-f) \cdot R-S] \geq & \\
& p \cdot\left[(E+S) \cdot\left[(1-\bar{x}(w, S)) \cdot(1-\bar{f}) \cdot R_{f}+\bar{x}(w, S) \cdot R\right]-S\right] .
\end{aligned}
$$

This inequality holds as an equality for a threshold fee

$$
f_{t h r, i i}^{(T=0)}(w):=\frac{R-(1-\bar{f}) \cdot R_{f}}{R} \cdot(1-\bar{x}(w, S)) .
$$

If the rater sets a fee above this threshold, then the bank will not agree on ratings inflation but will force the rater to rate truthfully $(T=1)$. Subjected to the bank's participation constraint the rater optimally sets $f^{*}(T=0)=f_{t h r, i i}^{(T=0)}(w)$. 
It remains to verify that the bank indeed optimally chooses $D^{*}(w, T=0, f)=S$ and $x^{*}(w, T=0, f)=1$ conditional on $T=0$ and $f \in\left\{f_{t h r, i}^{(T=0)}(w), f_{t h r, i i}^{(T=0)}(w)\right\}$. For $T=0$ the bank is free to choose any portfolio allocation $x$ because both issuers receive the good $A$-rating and so the regulatory constraint (9) never binds. By Lemma 1 it follows that the optimal portfolio allocation $x^{*}$ conditional on $T=0$ must be in the set $\{0,1\}$.

Conditional on $D$, direct calculations show that the bank optimally chooses $x^{*}=1$ if and only if $D$ exceeds some threshold $E \cdot \frac{R_{f}-p \cdot R}{p \cdot(R-1)-\left(R_{f}-1\right)+(1-p) \cdot \frac{f}{1-f}}$. From Inequality (2) it follows that $S$ exceeds this threshold for any non-negative fee $f$. As the bank's expected shareholder payoff for $x=1$ is strictly increasing in $D$ and the bank's participation constraint is satisfied, the bank optimally chooses $D^{*}=S$ and $x^{*}=1$. This completes the proof.

\section{Proof that $T^{*}=O$ under RCCR for $P=O$}

I need to check for which risk-weights $w$ Inequality (11) holds. For $w \geq w_{t h r}^{(T=1)}(11)$ becomes

$$
\begin{array}{ccll} 
& \pi_{R A}\left(T=0, f_{t h r, i}^{(T=0)}(w)\right) & >\pi_{R A}\left(T=1, f^{*}(w, T)\right) \\
\Leftrightarrow & (E+S) \cdot f_{t h r, i}^{(T=0)}(w) & >(E+S) \cdot f^{*}(w, T=1) \\
\Leftrightarrow & f_{t h r, i}^{(T=0)}(w) & >f^{*}(w, T=1)
\end{array}
$$

where $f^{*}(w, T=1)$ is determined by Lemma 7 . By Inequality (2) this last inequality is true and the rater optimally inflates the quality of its ratings for $w \geq w_{t h r}^{(T=1)}$. For $w<w_{t h r}^{(T=1)}$ Inequality (11) becomes

$$
\begin{array}{rlll} 
& \pi_{R A}\left(T=0, f_{t h r, i i}^{(T=0)}(w)\right) & >\pi_{R A}(T=1, \bar{f}) \\
\Leftrightarrow & & (E+S) \cdot f_{t h r, i i}^{(T=0)}(w) & >(E+S) \cdot(1-\bar{x}(w, S)) \cdot \bar{f} \\
\Leftrightarrow & R & >R_{f}
\end{array}
$$

which is true.

\section{Proof to Lemma 4}

$$
P_{t h r}\left(w \geq w_{t h r}^{(T=1)}\right)=\frac{S}{p \cdot R}-\frac{E+S}{1-p}\left(\frac{1}{p \cdot R}-\frac{1}{R_{f}}\right) \cdot \frac{S \cdot(1-p) \cdot w+E \cdot p \cdot R}{S \cdot(1-p) \cdot w+E \cdot(p \cdot(1-w)+w)}
$$

It is easy to show that $P_{t h r}(w)$ increases in the risk-weight $w$. 
Part (a):

For $w<w_{t h r}^{(T=1)}$ the bank chooses

- $x^{*}=\bar{x}$ if $P \geq P_{t h r}(w)$.

- $x^{*}=1$ if $P<P_{t h r}(w)$.

In both cases welfare is negative. For $w \geq w_{t h r}^{(T=1)}$

- $T^{*}=0$ and $x^{*}=1$ if $P<P_{t h r}(w)$ and welfare is negative.

- $T^{*}=1$ and $x^{*}=0$ if $P \geq P_{t h r}(w)$ and welfare is positive.

Part (b):

For $P \geq P_{t h r}(w)$ and $w \geq w_{t h r}^{(T=1)}$ the rater is benevolent $\left(T^{*}=1\right)$ according to Proposition 3 . Under RCCR with a benevolent rater, the regulator optimally chooses $w=w_{t h r}^{(T=1)}$ according to Proposition 2.

\section{E Welfare Higher under RCCR and $T=1$ than under RICR}

Welfare is higher under RCCR than under RICR only if

1. the rater optimally chooses $T^{*}=1\left(\Leftrightarrow P \geq P_{t h r}(w)\right)$,

2. the bank optimally chooses $x^{*}=0\left(\Leftrightarrow w \geq w_{t h r}^{(T=1)} \& T^{*}=1\right)$.

These conditions prove sufficient for RCCR to maximize welfare provided that

$$
S \geq E \cdot \frac{R_{f}-p \cdot R_{f}}{p(R-1)-\left(R_{f}-1\right)}
$$

Direct calculations show that welfare is higher under RCCR than under RICR for any nonnegative risk-weight $w, T^{*}=1, x^{*}=0$, and the above inequality:

$$
\begin{gathered}
W\left(f_{t h r}^{(T=1)}(w), D^{*}=S, x^{*}=0\right)>W\left(\bar{D}=D_{t h r}^{I}=D^{*}, x^{*}=0\right) \\
\Leftrightarrow(E+S) \cdot\left(1-f^{*}(w, T=1)\right) \cdot\left(R_{f}-1\right)>\left(E+D_{t h r}^{I}\right)\left(R_{f}-1\right) \\
\Leftrightarrow w \cdot \underbrace{\left[E \cdot \frac{R_{f} \cdot(1-p)}{p \cdot(R-1)-\left(R_{f}-1\right)}-S\right]}_{\leq 0 \text { for } S \geq E \cdot \frac{R_{f}-p \cdot R_{f}}{p(R-1)-\left(R_{f}-1\right)}}<\underbrace{\left[R-\frac{E}{E+S} \cdot \frac{(1-p) \cdot R_{f}}{p \cdot(R-1)-\left(R_{f}-1\right)}\right] \cdot E \cdot \frac{p}{1-p}}_{>0}
\end{gathered}
$$


The case in which $S<E \cdot \frac{R_{f}-p \cdot R_{f}}{p(R-1)-\left(R_{f}-1\right)}$ is more complicated. Provided that $T^{*}=1$ and $x^{*}=0$, welfare is higher under RCCR than under RICR if and only if $w<w_{R C C R}$ where $w_{R C C R}$ is given as

$$
w_{R C C R}:=\frac{E}{E+S} \cdot \frac{p}{1-p} \cdot \frac{R \cdot(E+S) \cdot\left[p \cdot(R-1)-\left(R_{f}-1\right)\right]-E \cdot(1-p) \cdot R_{f}}{E \cdot R_{f} \cdot(1-p)-S \cdot\left[p \cdot(R-1)-\left(R_{f}-1\right)\right]} .
$$

As $x^{*}=0$ requires $w \geq w_{t h r}^{(T=1)}($ Lemmas 6 and 7$)$, I need $w_{R C C R}>w_{t h r}^{(T=1)}$. As $w_{t h r}^{(T=1)}$ increases in the rater's market power $\bar{f}$, there exists a sufficiently small value of $\bar{f}$-call it $\hat{\bar{f}}$ - such that $w_{R C C R}>w_{t h r}^{(T=1)}(\hat{\bar{f}})$. Furthermore, note that $f\left(w_{R C C R}\right)$ is positive which follows from the observation that $W(R C C R, T=1, D=S, x=0)>W(R I C R)$ for $f=0$. Consequently, $\hat{\bar{f}}$ can be chosen such that $f^{*}\left(w_{t h r}^{(T=1)}(\hat{\bar{f}})\right)>0$. Direct calculation shows that $w_{R C C R}$ satisfies the requirement $w>\frac{E}{E+S}$ (Inequality (8)) thanks to Inequality (2). Consequently, $\hat{\bar{f}}$ can be chosen such that $w_{t h r}^{(T=1)}(\hat{\bar{f}})$ satisfies Inequality (8), too. 


\section{References}

Admati, Anat R., DeMarzo, Peter M., Hellwig, Martin F., \& Pfleiderer, Paul C. 2011 (August). Fallacies, Irrelevant Facts, and Myths in the Discussion of Capital Regulation: Why Bank Equity is Not Expensive. Working Paper. Stanford University \& Max Planck Institute for Research on Collective Goods.

Admati, Anat R., DeMarzo, Peter M., Hellwig, Martin F., \& Pfleiderer, Paul C. 2012 (March). Debt Overhang and Capital Regulation. Working Paper. Stanford University \& Max Planck Institute for Research on Collective Goods.

Adrian, Tobias, \& Shin, Hyun Song. 2012 (March). Procyclical Leverage and Value-at-Risk. Working Paper. Federal Reserve Bank of New York.

BCBS. 2006 (June). International Convergence of Capital Measurement and Capital Standards. Revised Framework. http://www.bis.org/publ/bcbs128.pdf.

BCBS. 2009 (December). Strengthening the Resilience of the Banking Sector. Consultative Document. http://www.bis.org/publ/bcbs164.pdf?noframes=1.

Benmelech, Efraim, \& Dlugosz, Jennifer. 2009. The Credit Rating Crisis. NBER Macroeconomics Annual 2009, 24, 161-207.

Bolton, Patrick, Freixas, Xavier, \& Shapiro, Joel. 2012. The Credit Ratings Game. The Journal of Finance, 67(1), 85-112.

Brister, Bill M., Kennedy, Robert E., \& Liu, Pu. 1994. The Regulation Effect of Credit Ratings on Bond Interest Yield: The Case of Junk Bonds. Journal of Business Finance E Accounting, 21(4), 511-531.

Brunnermeier, Markus K. 2009. Deciphering the Liquidity and Credit Crunch 2007-2008. Journal of Economic perspectives, 23(1), 77-100.

Brunnermeier, Markus K., Crocket, Andrew, Goodhart, Charles, Persaud, Avinash D., \& Shin, Hyun. 2009 (January). The Fundamental Principles of Financial Regulation. Geneva Reports on the World Economy 11. International Center for Monetary and Banking Studies.

Calomiris, Charles W. 2009 (October). The Debasement of Ratings: What's Wrong and How We Can Fix It. Working Paper. Columbia Business School. 
Cantor, Richard, Gwilym, Owain Ap, \& Thomas, Stephen H. 2007. The Use of Credit Ratings in Investment Management in the U.S. and Europe. Journal of Fixed Income, $\mathbf{1 7}(2), 13-26$.

Chen, Zhihua, Lookman, Aziz A., Schürhoff, Norman, \& Seppi, Duane J. 2012 (July). Why Ratings Matter: Evidence from the Lehman Brothers Index Rating Redefinition. Working Paper. University of Shanghai, Pittsburgh, Lausanne, Carnegie Mellon.

Deutscher Bundestag. 2011 (November). Ratingagenturen besser regulieren. Entschließungsantrag 17/7638. http://dipbt.bundestag.de/dip21/btd/17/076/ 1707638.pdf.

Diamond, Douglas W. 1984. Financial Intermediation and Delegated Monitoring. The Review of Economic Studies, 51(3), 393-414.

Diamond, Douglas W., \& Dybvig, Philip H. 1983. Bank Runs, Deposit Insurance, and Liquidity. Journal of Political Economy, 91(3), 401-419.

European Commission. 2011 (November). Proposal for a regulation of the European Parliament and of the Council amending regulation (EC) No 1060/2009 on credit rating agencies. Proposal European Commission. http://ec.europa.eu/internal_market/securities/ docs/agencies/COM_2011_747_en.pdf.

Faure-Grimaud, Antoine, Peyrache, Eloïc, \& Quesada, Lucía. 2009. The Ownership of Ratings. The RAND Journal of Economics, 40(2), 234-257.

Giammarino, Ronald M., Lewis, Tracy R., \& Sappington, David E. M. 1993. An Incentive Approach to Banking Regulation. The Journal of Finance, 48(4), 1523-1542.

Gorton, Gary B. 2009. Slapped in the Face by the Invisible Hand: Banking and the Panic of 200\%. Working Paper. Yale School of Management.

Harris, Milton, Opp, Christian, \& Opp, Marcus. 2013. Rating Agencies in the Face of Regulation. Journal of Financial Economics, 108(1), 2013.

Hau, Harald, Langfield, Sam, \& Marques-Ibanez, David. 2013. Banks' Credit Ratings: What Determines their Quality? Economic Policy, (forthcoming). 
He, Jie, Qian, Jun, \& Strahan, Philip E. 2011. Credit Ratings and the Evolution of the Mortgage-Backed Securities Market. The American Economic Review: Papers 83 Proceedings, 101(3), 131-135.

Hellmann, Thomas F., Murdock, Kevin C., \& Stiglitz, Joseph E. 2000. Liberalization, Moral Hazard in Banking, and Prudential Regulation: Are Capital Requirements Enough? The American Economic Review, 90(1), 147-165.

Hellwig, Martin. 2009. Systemic Risk in the Financial Sector: An Analysis of the SubprimeMortgage Financial Crisis. De Economist, 157, 129-207.

Hellwig, Martin F. 2010 (July). Capital Regulation after the Crisis: Business as Usual? Preprints of the Max Planck Institute for Research on Collective Goods 31. Max Planck Institute for Research on Collective Goods.

Hirth, Stefan. 2012 (August). Credit Rating Dynamics and Competition. Working Paper. Aarhus University.

Holmstrom, Bengt, \& Tirole, Jean. 1997. Financial intermediation, loanable funds, and the real sector. The Quarterly Journal of Economics, 112(3), 663-691.

Hunt, John P. 2009. Credit Rating Agencies and the 'Worldwide Credit Crisis': The Limits of Reputation, the Insufficiency of Reform, and a Proposal for Improvement. Columbia Business Law Review, 2009(1), 109-209.

John, Kose, John, Teresa A., \& Senbet, Lemma W. 1991. Risk-shifting incentives of depository institutions: A new perspective on federal deposit insurance reform. Journal of Banking and Finance, 15(4-5), 895-915.

Kisgen, Darren J., \& Strahan, Philip E. 2010. Do Regulations Based on Credit Ratings Affect a Firm's Cost of Capital? Review of Financial Studies, 23(12), 4324-4347.

Lucas, Robert E. 1976. Econometric Policy Evaluation: A Critique. Pages 19-46 of: Brunner, K., \& Meltzer, A. H. (eds), The Phillips Curve and Labor Markets. Carnegie-Rochester Conferences on Public Policy.

Mählmann, Thomas. 2008. Rating agencies and the role of rating publication rights. Journal of Banking and Finance, 32(11), 2412-2422. 
Mathis, Jérôme, McAndrews, James, \& Rochet, Jean-Charles. 2009. Rating the raters: Are reputation concerns powerful enough to discipline rating agencies? Journal of Monetary Economics, 56(5), 657-674.

Miller, Merton H. 1977. Debt and Taxes. The Journal of Finance, 32(2), 261-275.

Modigliani, Franco, \& Miller, Merton H. 1958. The Cost of Capital, Corporation Finance, and the Theory of Investment. The American Economic Review, 48(3), 261-297.

Myers, Stewart C. 1977. Determinants of corporate borrowing. Journal of Financial Economics, 5(2), 147-175.

Myers, Stewart C., \& Majluf, Nicholas S. 1984. Corporate financing and investment decisions when firms have information that investors do not have. Journal of Financial Economics, $\mathbf{1 3}(2), 187-221$.

Pagano, Marco, \& Volpin, Paolo. 2010. Credit ratings failures and policy options. Economic Policy, 25(62), 401-431.

Poon, Winnie P. H., \& Firth, Michael. 2005. Are Unsolicited Credit Ratings Lower? International Evidence From Bank Ratings. Journal of Business Finance $\mathscr{G}$ Accounting, 32(9-10), 1741-1771.

Rochet, Jean-Charles. 1992. Capital requirements and the behaviour of commercial banks. European Economic Review, 36(5), 1137-1170.

Sangiorgi, Francesco, Sokobin, Jonathan, \& Spatt, Chester. 2009 (June). Credit-Rating Shopping, Selection and the Equilibrium Structure of Ratings. Working Paper. Carnegie Mellon University.

Securities and Exchange Commission (SEC). 2008. Summary Report of Issues Identified in the Commission Staff's Examinations of Select Credit Rating Agencies. Summary Report. http://www.sec.gov/news/studies/2008/craexamination070808.pdf.

Skreta, Vasiliki, \& Veldkamp, Laura. 2009. Ratings Shopping and Asset Complexity: A Theory of Ratings Inflation. Journal of Monetary Economics, 56(5), 678-695.

Stolper, Anno. 2009. Regulation of credit rating agencies. Journal of Banking and Finance, 33(7), 1266-1273. 
US Congress. 2010 (July). Dodd-Frank Wall Street Reform and Consumer Protection Act. Public Law 111-203, H.R. 4173, Section 932. http://www.gpo.gov/fdsys/pkg/ PLAW-111pub1203/pdf/PLAW-111pub1203.pdf.

White, Lawrence J. 2010. Markets: The Credit Rating Agencies. The Journal of Economic Perspectives, 24(2), 211-226. 